\title{
Fibrocytes: A Critical Review and Practical Guide
}

\author{
James W. Reinhardt ${ }^{1 *}$ and Christopher K. Breuer ${ }^{1,2,3}$ \\ ${ }^{1}$ Center for Regenerative Medicine, Abigail Wexner Research Institute, Nationwide Children's Hospital, Columbus, OH, \\ United States, 2 Department of Surgery, The Ohio State University Wexner Medical Center, Columbus, OH, United States, \\ ${ }^{3}$ Department of Surgery, Nationwide Children's Hospital, Columbus, $\mathrm{OH}$, United States
}

Fibrocytes are hematopoietic-derived cells that directly contribute to tissue fibrosis by producing collagen following injury, during disease, and with aging. The lack of a fibrocytespecific marker has led to the use of multiple strategies for identifying these cells in vivo. This review will detail how past studies were performed, report their findings, and discuss their strengths and limitations. The motivation is to identify opportunities for further investigation and promote the adoption of best practices during future study design.

Keywords: fibrocytes, collagen, myofibroblasts, bone marrow chimera, lineage tracing

OPEN ACCESS

Edited by:

Yang Jin,

Boston University, United States

Reviewed by:

Stanley Hoffman,

Medical University of South Carolina,

United States

Thomas N. Wight,

Benaroya Research Institute, United

States

*Correspondence:

James W. Reinhardt

james.reinhardt@

nationwidechildrens.org

Specialty section:

This article was submitted to Inflammation,

a section of the journal

Frontiers in Immunology

Received: 27 September 2021 Accepted: 30 November 2021 Published: 17 December 2021

Citation:

Reinhardt JW and Breuer CK (2021) Fibrocytes: A Critical Review and Practical Guide.

Front. Immunol. 12:784401. doi: 10.3389/fimmu.2021.784401

\section{INTRODUCTION}

Fibrocytes are hematopoietic-derived cells that directly contribute to fibrosis of tissues throughout the body by producing collagen following injury, during disease, and with aging. While fibrocytes can be isolated from peripheral blood and enriched in culture, the lack of a fibrocyte-specific marker has challenged study of this cell type in vivo. One of the most common approaches has been to use bone marrow (BM) chimera models that enable tracking of hematopoietic-derived cells. However, by focusing on cells recently derived from the circulation some studies have overlooked hematopoietic-derived tissue resident populations. In addition, immunolabeling against type I collagen (Col1) has been performed to identify collagen expression without validation of expression by a secondary method. This is problematic because macrophages from which fibrocytes may be derived can degrade collagen and take up collagen fragments from their environment. Immunolabeling against Coll only shows whether the protein is within the cell and does not distinguish whether this collagen has been produced by the cell or taken up (1-3). Therefore, on the one hand some studies may have under-identified fibrocytes, and on the other hand studies may have over-identified hematopoietic cells that produce collagen by falsely identifying macrophages with internalized collagen as fibrocytes. The field recognizes and has begun to address these limitations by using transgenic mouse models, immunolabeling against more robust targets of collagen production, such as collagen propeptides, and validating collagen expression by performing transcriptional analyses. Most recently, single-cell RNA sequencing (scRNA-Seq) has been applied to study macrophage fibroblastic differentiation and collagen production. This approach provides a broad and quantitative measurement of gene transcription, enhancing the ability to identify and

Abbreviations: BM, Bone marrow; Colla1, procollagen type I $\alpha 1$; Colla2, procollagen type I $\alpha 2$; DT, diphtheria toxin; HSC, hematopoietic stem cell; MSC, mesenchymal stem cell; PBMC, peripheral blood mononuclear cell; PICP, procollagen type I Cterminal propeptide; PINP, procollagen type I N-terminal propeptide; scRNA-Seq, single-cell RNA-Sequencing; UUO, unilateral ureteral obstruction. 
characterize cells, thereby overcoming many limitations common among in vivo studies of fibrocytes.

In anticipation of a new era demarcated by the application of next generation sequencing and single-cell transcriptional analysis, now seems an appropriate moment to revisit what has been learned about fibrocytes and also how that knowledge was acquired to promote the application of best practices moving forward. This review will begin by detailing the methods that have been used to study fibrocytes including immunolabeling, transgenic mice, parabiosis models, and transcriptional analyses. Examples will be provided that cover several tissues throughout the body including skin, heart, lung, kidney, and liver. Through doing so, the intent is to familiarize the reader with the strengths and limitations of these methods as well as tissue-specific differences. Following next, efforts to quantify the relative amount of collagen production by fibrocytes, compared to traditional fibrogenic cells, and characterize fibrocyte-derived myofibroblasts will be summarized. Last, potential origins of fibrocytes and sites of fibrocyte differentiation will be discussed.

\section{BACKGROUND}

Fibrocytes were first described in 1994 after observing spindleshaped, adherent, fibroblast-like cells within subcutaneous wound chambers in mice (4). While fibroblasts are known to invade wound chambers from the surrounding tissue, these fibrocytes were observed acutely, within 2 days, coincident with the influx of peripheral blood cells and in an "unexpectedly large number". The timing and abundance of these cells led the authors to conclude "this cell population was arising from peripheral blood and not exclusively by slow migration from adjacent connective tissue". Cells isolated from the wound chamber were reported to have expressed Col1, as determined by immunolabeling, but lacked non-specific esterases indicating they were distinct from adherent peripheral blood monocytes. To follow up on the hypothesis that these fibrocytes were circulation-derived, human peripheral blood mononuclear cells (PBMCs) isolated by density gradient centrifugation were studied in tissue culture. Following plating, on the day these cells were isolated $\sim 0.25 \%$ were Col1 + CD $34+$. Adherent cells were then cultured for 2-4 weeks in serumsupplemented medium under conditions that selected for plastic adherence. This resulted in enrichment of Col1+ CD34+ cells with an elongated morphology that also expressed the myeloid integrin CD11b as well as mesenchymal markers vimentin and fibronectin. These cells did not express epithelial, endothelial, or SMC markers, but did express leukocyte common antigen (CD45). When revisiting the wound chamber assay, 10 days after implantation $10-15 \%$ of cells in the wound chamber were Col1+ CD34+. Expression of CD34, also called hematopoietic stem cell (HSC) antigen, suggested these were blood-borne cells. The potential hematopoietic origin led the authors to explore the possibility that fibrocytes might arise from hematopoietic progenitors by utilizing a sex-mismatched BM chimeric mouse model. However, using the same wound chamber assay, Col1 $+\mathrm{CD} 34+$ cells of host origin only were detected; no Coll $+\mathrm{CD} 34+$ donor BM-derived cells were observed. The authors interpreted these results as "these data suggest that blood-borne fibrocytes do not originate from radiosensitive, hematopoietic stem cells but arise instead from either a radioresistant, bone marrow progenitor cell or from other tissue sources". Unfortunately, the authors did not determine whether fibrocytes could be derived from donorderived PBMCs in chimeric mice. This would have shown that fibrocytes in the wound chamber and those isolated from the peripheral blood might be distinct populations. However, subsequent studies have identified donor BM-derived fibrocytes in other tissues including a HSC-derived fibrocytes in a dermal wound healing model suggesting the absence of donor BMderived fibrocytes in the subcutaneous wound chamber may have been an assay specific finding (5).

\subsection{Methods to Study Fibrocytes}

The lack of a fibrocyte-specific marker has posed challenges to the investigation of this cell type in vivo. As a result, different strategies have been employed to study the contribution of fibrocytes to injury and disease models. These include: 1) immunolabeling, 2) labeling of circulating cells, 3) transgenic mice, and 4) transcriptional analysis which will be detailed in the following sections.

\subsubsection{Immunolabeling}

A common practice and limitation among studies of fibrocytes is the reliance on immunolabeling against Col1 as evidence of Col1 expression without validation of gene expression or protein production by a secondary method (Table 1). Validation is critical because immunolabeling only shows whether the protein is within the cell and does not distinguish whether this collagen has been produced by the cell or taken up from its environment (Figure 1) (6). Efficient uptake of collagen is believed to be a feature unique to mesenchymal cells with macrophages as the exception which can degrade collagen and uptake collagen fragments from their surroundings mediated by the M2 macrophage marker CD206 (1-3). To provide more context, the fundamental structural unit of Coll is a triple helix comprised of two procollagen type I $\alpha 1$ (pColla1) chains and a single $\alpha 2$ (pCol1a2) chain. Each procollagen chain is flanked by procollagen type I C-terminal propeptide (PICP) and $\mathrm{N}$-terminal propeptide (PINP) which are cleaved off in the extracellular space before a Coll monomer can be incorporated into a fibril. Antibodies against Col1 are typically polyclonal, derived using purified Coll or a synthetic peptide corresponding to a sequence within Colla1 or Colla2 as an antigen. Therefore, these antibodies do not recognize PICP or PINP which distinguish procollagen produced by a cell from Coll that might have been taken up by the cell. While many studies report that positively immunolabeled cells "express" Coll, in this review cells that are positively immunolabeled will be identified by the target of immunolabeling followed by a “+' symbol (e.g., Col1+).

Assuming collagen propeptides cleaved off in the extracellular space are not taken up by hematopoietic-derived cells, these would be better markers to identify Coll production $(26,27)$. Positive immunolabeling for PINP and CD45 has been used to identify fibrocytes in punch biopsies taken from a human partial- 
TABLE 1 | Anti-collagen antibodies.

\section{Study Details}

Ref. Application(s)

Validation of Collagen Expression

(4) FACS Mouse Cells From Subcutaneous Wound No Chamber

ICC Human and Mouse Cultured PBMCs No

(6) WB, IF, Mouse Lung Cells and Cultured PBMCs GPCR $\mathrm{FC}$

(7) IF Human Dermal Wound Biopsy Sections

qPCR

(8) IF

(9) IF

Mouse Vascular Graft Tissue Sections

Mouse Lung Tissue Sections

NA

FC Human and Mouse PBMCs

In Situ Hybridization

No

(10) IF, FC Mouse Dermal Wound Biopsy Sections GPCR

WB Mouse Dermal Hematopoietic-Derived Cells

(11) ICC, FC Mouse Lung Cells and Lung Fibroblast Cultures

(12) IHC Mouse Cardiac Infarct Tissue Sections

(13) IF Mouse Dermal Granulation Tissue Sections

IF

Mouse Dermal Granulation Tissue

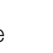

\section{Sections}

(14) FC

Mouse PBMCs, Spleen Cells, and Kidney No

$$
\text { Cells }
$$

IF Mouse Kidney Tissue Sections

(15) IF Human Peripheral Blood Monocytes

qPCR (Whole Tissue)

IHC Mouse Heart Tissue Sections

No

(16) IF, IHC, Human and Mouse Kidney Tissue WB Sections

FC Mouse Kidney Cells

(17) IF Mouse Heart Tissue Sections

(18) ICC, FC Human Cultured PBMCs

(19) ICC Mouse Cultured Spleen Cells

FC Mouse Cultured Spleen Cells No

(20) ICC, FC Human Cultured PBMC

(21) FC Human PBMCs

(22) ICC, FC Human Cultured PBMCs

FC Mouse BM Cells, Lung Cells, PBMCs

(23) IF

$$
\text { IF Human Heart Tissue Sections }
$$

IF Mouse Heart Tissue Sections

FC

Mouse Heart Cells

(24) ICC, IF Mouse Cultured BM Cells, Mouse BM

Tissue Sections

ICC, IF Mouse Cultured BM Cells, Mouse BM Tissue Sections

\begin{tabular}{|c|c|c|}
\hline Antibody (Immunogen) & Manufacturer & $\begin{array}{l}\text { Catalog } \\
\text { Number }\end{array}$ \\
\hline Anti-Collagen I & $\begin{array}{l}\text { Chemicon International } \\
\text { (Merck) }\end{array}$ & NS \\
\hline Anti-Collagen I & $\begin{array}{l}\text { Chemicon International } \\
\text { (Merck) }\end{array}$ & NS \\
\hline Anti-Collagen $\mathrm{I}^{\mathrm{A}}$ & $\begin{array}{l}\text { Rockland } \\
\text { Immunochemicals }\end{array}$ & $600-401-103$ \\
\hline Anti-PINP (M-58) & $\begin{array}{l}\text { Chemicon International } \\
\text { (Merck) }\end{array}$ & MAB1912 \\
\hline Anti-PICP & Sigma-Aldrich & ABT257 \\
\hline Anti-Procollagen I & $\begin{array}{l}\text { Santa Cruz } \\
\text { Biotechnology }\end{array}$ & NS \\
\hline $\begin{array}{l}\text { FITC-Conjugated Anti- } \\
\text { Collagen I }\end{array}$ & $\begin{array}{l}\text { Chemicon International } \\
\text { (Merck) }\end{array}$ & NS \\
\hline Anti-Collagen $\mathrm{I}^{\mathrm{B}}$ & Abcam & AB34710 \\
\hline Anti-Collagen $\mathrm{I}^{\mathrm{C}}$ & Abcam & AB21286 \\
\hline Biotinylated-Anti-Collagen $\mathrm{A}^{\mathrm{A}}$ & $\begin{array}{l}\text { Rockland } \\
\text { Immunochemicals }\end{array}$ & $600-406-103$ \\
\hline Anti-Collagen I & Abcam & NS \\
\hline Anti-Collagen I ${ }^{\mathrm{D}}$ & Abcam & AB19811 \\
\hline Anti-Collagen I ${ }^{B}$ & Abcam & AB34710 \\
\hline Biotinylated-Anti-Collagen $\mathrm{A}^{\mathrm{A}}$ & $\begin{array}{l}\text { Rockland } \\
\text { Immunochemicals }\end{array}$ & $600-406-103$ \\
\hline Anti-Collagen I & Abcam & NS \\
\hline $\begin{array}{l}\text { FITC-Conjugated Anti- } \\
\text { Collagen I }(4 \mathrm{~F} 6)^{\mathrm{E}}\end{array}$ & Southern Biotech & $1441-02$ \\
\hline Anti-Col1a1 $(H-197)^{F}$ & $\begin{array}{l}\text { Santa Cruz } \\
\text { Biotechnology }\end{array}$ & NS \\
\hline Anti-Collagen I & Southern Biotech & NS \\
\hline $\begin{array}{l}\text { FITC-Conjugated Anti- } \\
\text { Collagen I }\end{array}$ & NS & NS \\
\hline Anti-Col1a & Abcam & NS \\
\hline Anti-PINP (M-58) & $\begin{array}{l}\text { Chemicon International } \\
\text { (Merck) }\end{array}$ & MAB1912 \\
\hline Anti-Collagen $I^{A}$ & $\begin{array}{l}\text { Rockland } \\
\text { Immunochemicals }\end{array}$ & $600-401-103$ \\
\hline Anti-Collagen $\left.\right|^{\mathrm{B}}$ & Abcam & AB292 \\
\hline Biotinylated-Anti-Collagen $\mathrm{A}^{\mathrm{A}}$ & $\begin{array}{l}\text { Rockland } \\
\text { Immunochemicals }\end{array}$ & $600-406-103$ \\
\hline Anti-Collagen $\mathrm{I}^{\mathrm{A}}$ & $\begin{array}{l}\text { Rockland } \\
\text { Immunochemicals }\end{array}$ & $600-401-103$ \\
\hline Anti-Collagen I & $\begin{array}{l}\text { Chemicon International } \\
\text { (Merck) }\end{array}$ & NS \\
\hline Anti-Collagen I & $\begin{array}{l}\text { Chemicon International } \\
\text { (Merck) }\end{array}$ & NS \\
\hline Anti-Collagen $I^{A}$ & $\begin{array}{l}\text { Rockland } \\
\text { Immunochemicals }\end{array}$ & $600-401-103$ \\
\hline Anti-PICP (A-17) & $\begin{array}{l}\text { Santa Cruz } \\
\text { Biotechnology }\end{array}$ & SC25973 \\
\hline Biotinylated-Anti-Collagen $\mathrm{I}^{\mathrm{A}}$ & $\begin{array}{l}\text { Rockland } \\
\text { Immunochemicals }\end{array}$ & $600-401-103$ \\
\hline Anti-Collagen $I^{G}$ & Abcam & AB6308 \\
\hline Anti-Collagen $I^{B}$ & Abcam & AB34710 \\
\hline
\end{tabular}

Antibody Information

(Continued) 
TABLE 1 | Continued

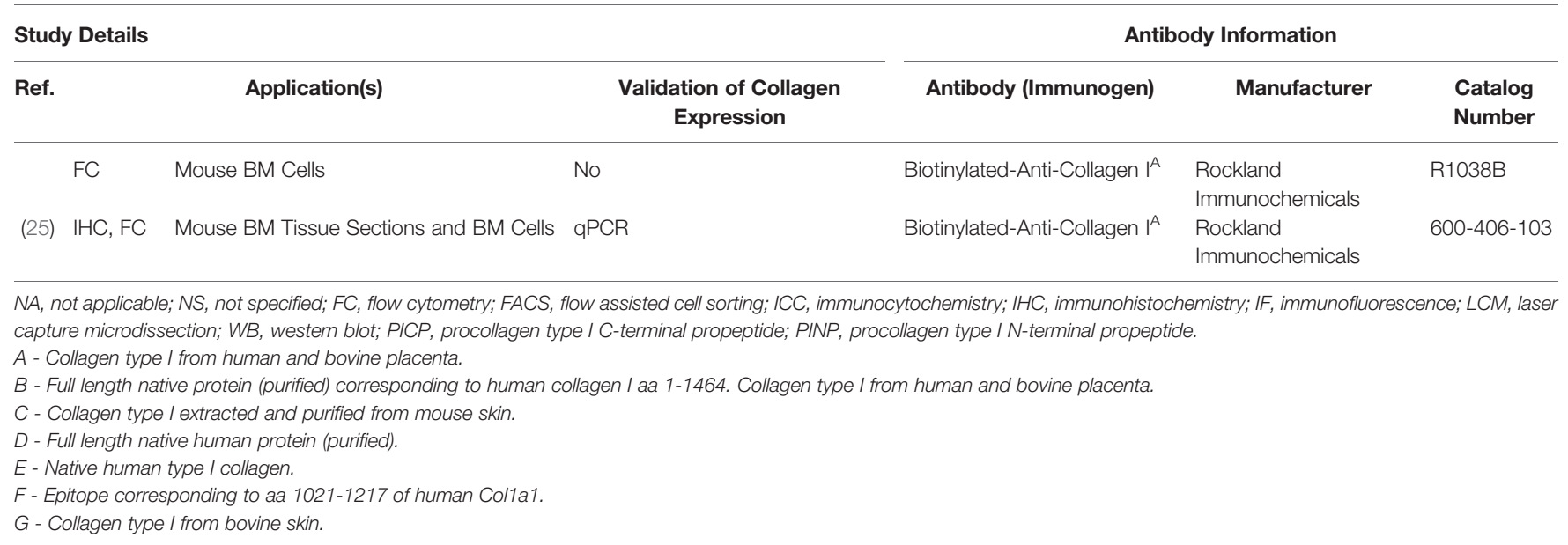

thickness dermal wounds caused by laser injury (7). One week after injury, in the upper dermis $15 \%$ of CD45+ cells were PINP+, accounting for $25.8 \%$ of total PINP+ cells. Three weeks following wounding, there were fewer CD45+ cells and PINP immunolabeling of $\mathrm{CD} 45+$ cells was not detected indicating a transient presence of CD45+ PINP+ cells in this model. Expression of pCollal was confirmed by laser capture microdissection and immunomagnetic selection of CD45+ cells with mRNA expression measured by quantitative polymerase chain reaction (qPCR).

Unlike dermal wounds that resolve relatively quickly, implanted biomaterials trigger a foreign body response and prolonged inflammation. In a murine tissue engineered vascular graft abdominal inferior vena cava interposition model, fibrocytes were identified by immunolabeling for the mouse macrophage marker F4/80 and PICP (8). Three days after implanting bioresorbable polyester scaffolds, $\sim 30 \%$ of $\mathrm{F} 4 / 80+$ cells were PICP+ and this increased to more than $80 \%$ of F $4 / 80+$ cells at day 14 . The persistence of fibrocytes throughout longer periods of implantation and following complete scaffold degradation was not determined, so it is unclear whether these cells persist at the site of chronic inflammation or, like fibrocytes in the aforementioned resolving dermal injury model, have a transient presence.

In situ hybridization is a technique that can be used to identify gene expression within a histological section, overcoming the limitation of Coll immunolabeling. By this method, a fluorophore labeled single-stranded RNA probe will localize to mRNA containing a complementary sequence. In biopsies of bronchial mucosa from patents with allergic asthma, to identify fibrocytes in situ hybridization for Collal was performed complementary to immunolabeling for CD34 (9). The rationale for identifying fibrocytes based on Collal and CD34 expression relied on cited literature asserting that fibrocytes are the only cell type to express these two markers, which has since proven to be inaccurate. CD34 and Colla1 are also expressed by interstitial fibroblasts, mesenchymal stem cells (MSCs), and adventitial smooth muscle progenitors, though acquired expression of CD45 has not been reported on these cells (28-31). This study did not evaluate whether these Colla1 expressing CD34+ cells also expressed any hematopoietic markers.

\subsubsection{Labeling Circulating Cells}

Labeling circulating cells has been used to demonstrate that fibrocytes contribute to intimal hyperplasia in an ovine carotid artery graft model using a gelatin-sealed Dacron graft (32). To label circulating cells, one day prior surgery $10 \%$ of the animal's blood was harvested and leukocytes were isolated by density gradient centrifugation. Leukocytes were labeled with the fluorescent marker carboxyfluorescein diacetate succinimidyl ester (CSFE) and immediately reinjected. Animals were then sacrificed at 1,2, and 4 weeks and grafts were analyzed by histology. Data to support the contribution of fibrocytes to intimal hyperplasia were presented as two pairs of images, one each at 2- and 4-weeks post implantation. Each pair consisted of one brightfield image of an immunohistochemical stain for alpha smooth muscle actin ( $\alpha \mathrm{SMA}$ ), using Vector Blue as the chromogen, and the same section was imaged by fluorescence microscopy for CSFE. These images appear to show a considerable presence by CSFE labeled circulating leukocytes in the neointima that are absent in animals without CSFE labeled cells. In addition, greater than $50 \%$ of CSFE labeled cells expressed $\alpha$ SMA at both time points. While $\alpha$ SMA expression could be interpreted to imply myofibroblastic differentiation of a fibroblast-like (i.e., matrix producing) precursor, assessment of collagen production by CSFE labeled cells was not confirmed in this study. Therefore, it is possible for $\alpha \mathrm{SMA}$ to have been expressed by these cells in the absence of collagen production and thus these cells were not rigorously identified as fibrocytes. A concern raised by the data presented is that the fractional area of CSFE labeling in the images seems far greater than would be expected based on labeling of $10 \%$ of circulating cells with CSFE unless the process of isolation and labeling were to greatly increase the propensity for these cells to preferentially home to the neointima compared to non-manipulated leukocytes. In addition, in the pair of 2-week images the overlap of $\alpha \mathrm{SMA}$ and CSFE staining appears near one-to-one and intensities of labeling are consistent. It may have been overlooked that Vector 


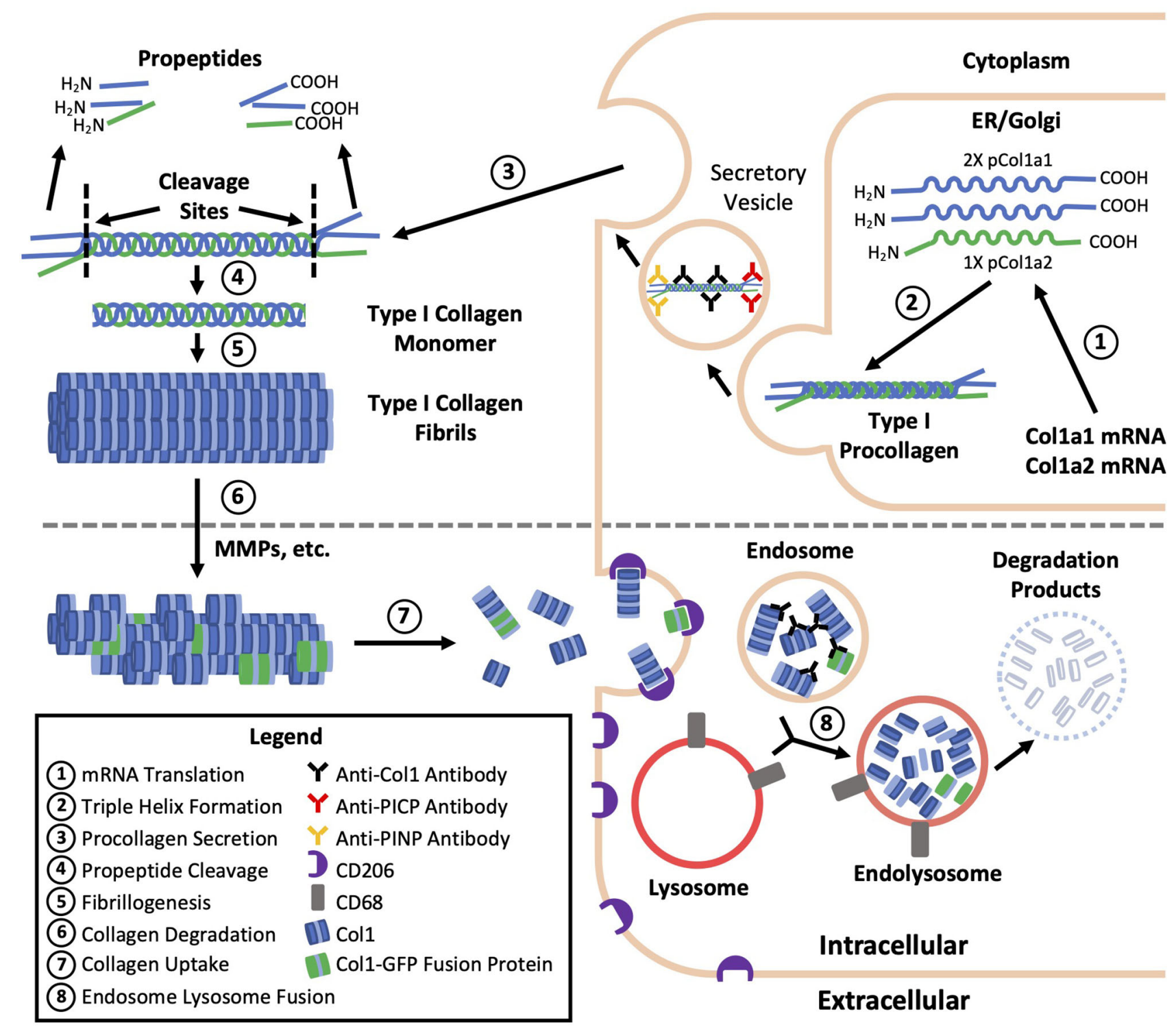

FIGURE 1 | Type I collagen production, degradation, and uptake. The fundamental structural unit of type I collagen (Col1) is a triple helix comprised of two procollagen type I a1 (pCol1a1) chains and a single a2 (pCol1a2) chain. Each procollagen chain is flanked by C-terminal propeptide (PICP) and N-terminal propeptide (PINP) which are cleaved off in the extracellular space before a Col1 monomer can be incorporated into a fibril. Antibodies against Col1 are typically polyclonal, derived using purified Col1 or a synthetic peptide corresponding to a sequence within Col1a1 or Col1a2 as an antigen. Therefore, these antibodies against Col1 (black) do not recognize PICP or PINP which distinguish procollagen produced by a fibrocyte (top) from Col1 taken up by a macrophage (bottom) leading to the misidentification of some macrophages as fibrocytes. Use of transgenic mice expressing a collagen-GFP fusion protein (green, bottom) may also result in fibrocyte misidentification as the collagen-GFP fusion protein may be taken up by macrophages and present in endosomes prior to further degradation.

Blue has broad excitation and emission spectra with peaks $\sim 500$ $\mathrm{nm}$ and $680 \mathrm{~nm}$ that overlap with the corresponding excitation and emission peaks for CSFE at $492 \mathrm{~nm}$ and $597 \mathrm{~nm}$, respectively (33). The 4-week images and images from the control animal without CSFE labeled cells do not show the same consistency between Vector Blue and CSFE labeling, but the positively stained cells display a relatively round morphology, not the typical spindle-shaped morphology that would be expected for $\alpha \mathrm{SMA}+$ myofibroblasts and fibroblasts or that is present in the 2week image.

These references to cell morphology within a histological section will be the first of many and the rationale for including this information will be provided here. During fibrocyte generation in culture from PBMCs, cell morphology provides some indication as to the state of differentiation since PBMCs are round at the time of plating and become elongated after adhesion 
and fibrocyte differentiation. Interpreting morphology from a histological section is less straightforward than for cells on a surface. A histological section is a cross-section of the 3dimensional geometry present in vivo. Therefore, a cell may have a non-round morphology, but appear round due to the plane of sectioning. However, the converse is not true; a cell that appears to have a non-round morphology is not round. For a hematopoietic-derived cell, an elongated or spindle-shaped morphology alone is not sufficient evidence of the state of fibrocyte differentiation as a non-spherical morphology may reflect the local environment or result from an active behavior such as migration through a dense matrix. Therefore, while observations of cell morphology are included, morphology is only intended to be complementary to less subjective evidence of cell phenotype.

Tissue infiltration of labeled fibrocytes was characterized in a mouse model of allergic asthma induced by ovalbumin (9). Col1+ CD34+ fibrocytes were isolated from peripheral blood by density gradient centrifugation, enriched by immunomagnetic depletion, labeled with the red fluorescent membrane dye PKH-26, then intravenously transfused into recipient mice. Within 4 hours, PKH-26 positive cells could no longer be detected in the peripheral blood. 24 hours after transplantation, flow cytometry performed on single cell suspensions from these lungs showed slightly decreased immunofluorescence intensity for CD34 and increased immunofluorescence intensities for Coll and $\alpha$ SMA on transplanted cells. Few labeled cells were observed in the lungs of PBS-treated control mice compared to the lungs of ovalbumin treated mice suggesting lung infiltration was a result of homing and not entrapment.

\subsubsection{Transgenic Mice}

Transgenic mice enable cell labeling and lineage-tracing studies by incorporating foreign DNA into the genome such that transcription of a particular gene results in transcription of the foreign DNA. Location of insertion may be in genes that are globally expressed in all cells or a subset of cells in which gene expression is restricted. Common proteins encoded by the foreign DNA include fluorescent proteins or enzymes that facilitate colorimetric reactions for labeling. Transgenes may also include recombinases that enact genetic alterations and different transgenic mice may be cross-bred so that their progeny possesses multiple transgenes. A commonly used method to perform lineage tracing is the conditional Cre-lox model in which Cre recombinase is expressed under the control of a promotor for a cell type-specific gene and a second transgene containing a reporter is preceded by a stop sequence flanked by two LoxP recombination sites, also referred to as floxed (fl). An example is Cre recombinase expressed under the promotor for myeloid-specific lysozyme M ( LyzM-Cre) using reporter green fluorescent protein (GFP) incorporated into the Rosa26 Cre reporter allele (R26R-GFP). Any cell expressing LyzM will also express Cre recombinase which will then excise the stop codon in the R26R Cre reporter allele (R26R to R26) allowing for GFP to be permanently expressed in that cell and its progeny. A disadvantage of conditional models is that if the cell-specific gene is expressed by a non-target cell type, as may occur during development or as a result of cell plasticity, the non-target cell and its progeny will also be permanently labeled with the reporter. For example, during wound healing and in cancer monocytes may express the endothelial marker Tie2 $(34,35)$.

A variation of lineage tracing is an inducible mouse model and one strategy by which this is done is by modifying the Cre transgene by fusing it to mutant estrogen ligand-binding domain (e.g., CreERT2). Only when a transgenic mouse expressing CreERT2 is treated with the estrogen mimetic tamoxifen will Cre translocate to the nucleus and induce recombination of the floxed sequence (36). Tamoxifen-dependent Cre recombinase allows for labeling to be performed at a specific time period during development or in an adult animal prior to a procedure, thus restricting recombination to a more highly-defined population of cells. A disadvantage of inducible Cre recombinase is "leakiness", or Cre activity without tamoxifen administration. This may be addressed by including appropriate controls in the experimental design. Proper controls are also important as tamoxifen alone might interfere with certain models, as it is has been observed to cause cardiac fibrosis and DNA damage, and Cre activation has been linked to toxicity (37-41).

Multi-transgenic mouse models increase cell specificity, however trade-offs include a lower efficiency of labeling and more complex breeding schemes (42). Complementary strategies used in combination with transgenic mice include adoptive cell transfer, tissue transplant, and parabiosis, allowing cells from the donor mouse to be identified within the recipient or distinguishing cells between parabionts. In addition to colorimetric or fluorescent reporters, donor and host cells may be distinguished by sex-mismatching or using alleles encoding different isoforms for a particular gene (e.g., CD45.1/CD45.2 and CD90.1/CD90.2). Many of the BM chimeric (Table 2) and other transgenic mouse models (Table 3) described in this review contain multiple transgenes. These will be listed in sequence separated by " $\mathrm{x}$ " to denote the cross-breeding that is typically done to generate multi-transgenic mice.

\subsubsection{BM Chimeric Mouse Models}

Since fibrocytes are hematopoietic-derived cells, in vivo studies of fibrocytes often utilize chimeric mice, generated by lethal irradiation to deplete host BM progenitor cells followed by BM reconstitution from a genetically distinct donor. This allows for distinguishing host cells from donor BM-derived cells and validation of this model typically reveals $>90 \%$ of $\mathrm{BM}$ and circulating cells are donor-derived. However, an often overlooked aspect of BM transplantation is that in addition to HSCs, BM also contains MSCs that may become entrapped in the capillary beds throughout the body including tissues in which fibrosis is often studied such as the lung, liver, kidney, spleen, heart, and muscle (61). BM-MSCs are $\sim 50 \%$ larger than BM hematopoietic cells and since BM transplantation is typically performed by intravenous infusion the pulmonary capillary bed will often be encountered first (62-64). Selective entrapment in the lungs imposes a limitation to the therapeutic use of intravenously delivered MSCs in other organs and limits BM engraftment $(29,65)$. The significance of BM-MSCs engrafting 
TABLE 2 | BM chimera models.

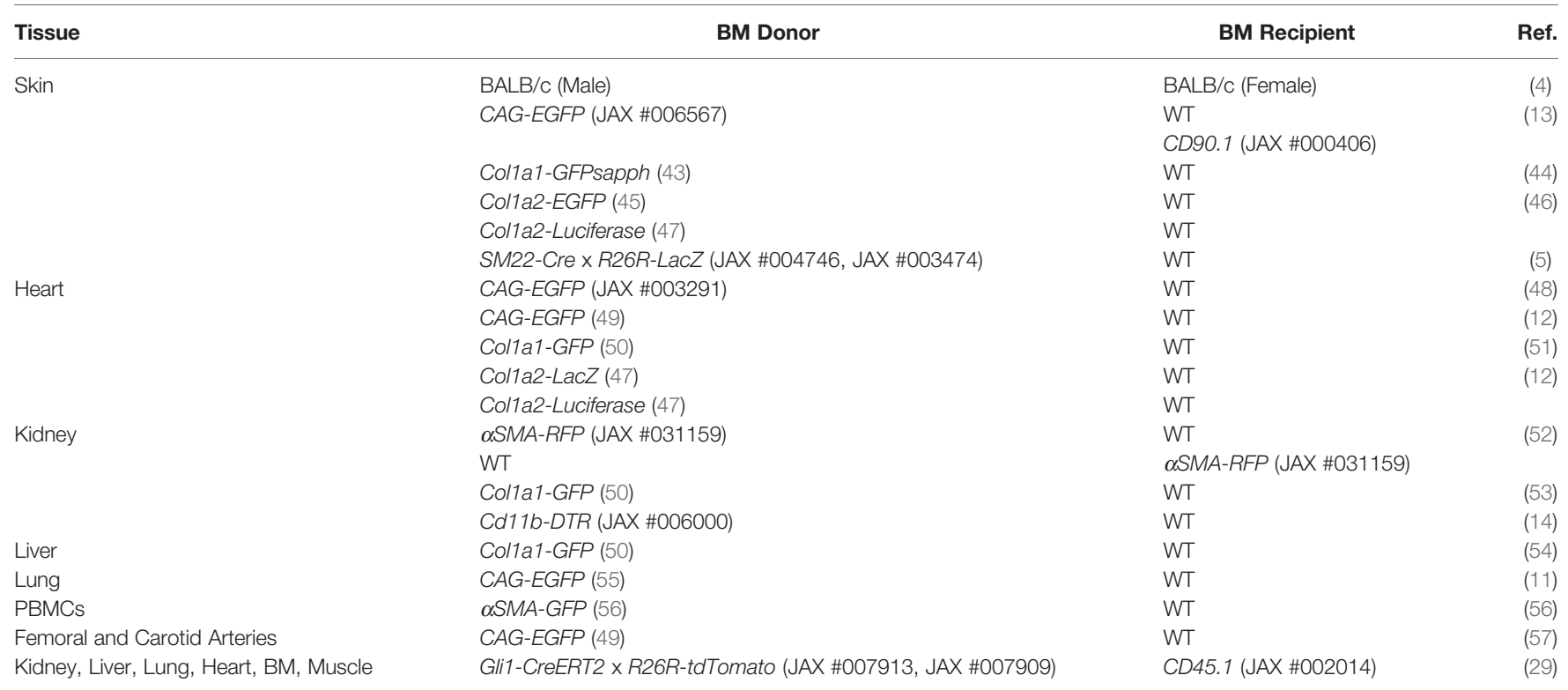

WT, wild type (C57BL/6); JAX, Jackson Laboratories.

within organs is that MSCs are predisposed toward a fibrogenic (i.e., matrix producing) myofibroblast lineage and contribute to fibrosis in many organs (29). Under normal conditions and following organ injury, BM-MSCs do not circulate and should not contribute to fibrosis outside of the BM $(29,66-68)$. For fibrocytes, stimuli in the target tissue can result in the loss of monocyte and macrophage surface marker expression during fibrocyte differentiation making it difficult to distinguish hematopoietic- and mesenchymal-derived cells (10). Thus, when using chimeric mice generated by BM transplantation to study organ fibrosis, entrapment of MSCs in organs may inflate the perceived contribution of hematopoietic BM-derived cells in organ fibrosis following injury or disease. As an example, Gli1 is expressed on perivascular MSCs including BM-MSCs. Mice with the CD45.1 isoform were lethally irradiated and reconstituted with whole BM from Gli1-CreERT2 x R26R-tdTomato x CD45.2 mice that were induced with tamoxifen prior to sacrifice and BM harvest (29). Following transplantation, only a small number of Gli1-derived donor cells were found in the BM and kidneys, but many had become entrapped in the lungs and could still be found

TABLE 3 | Other transgenic mouse models.

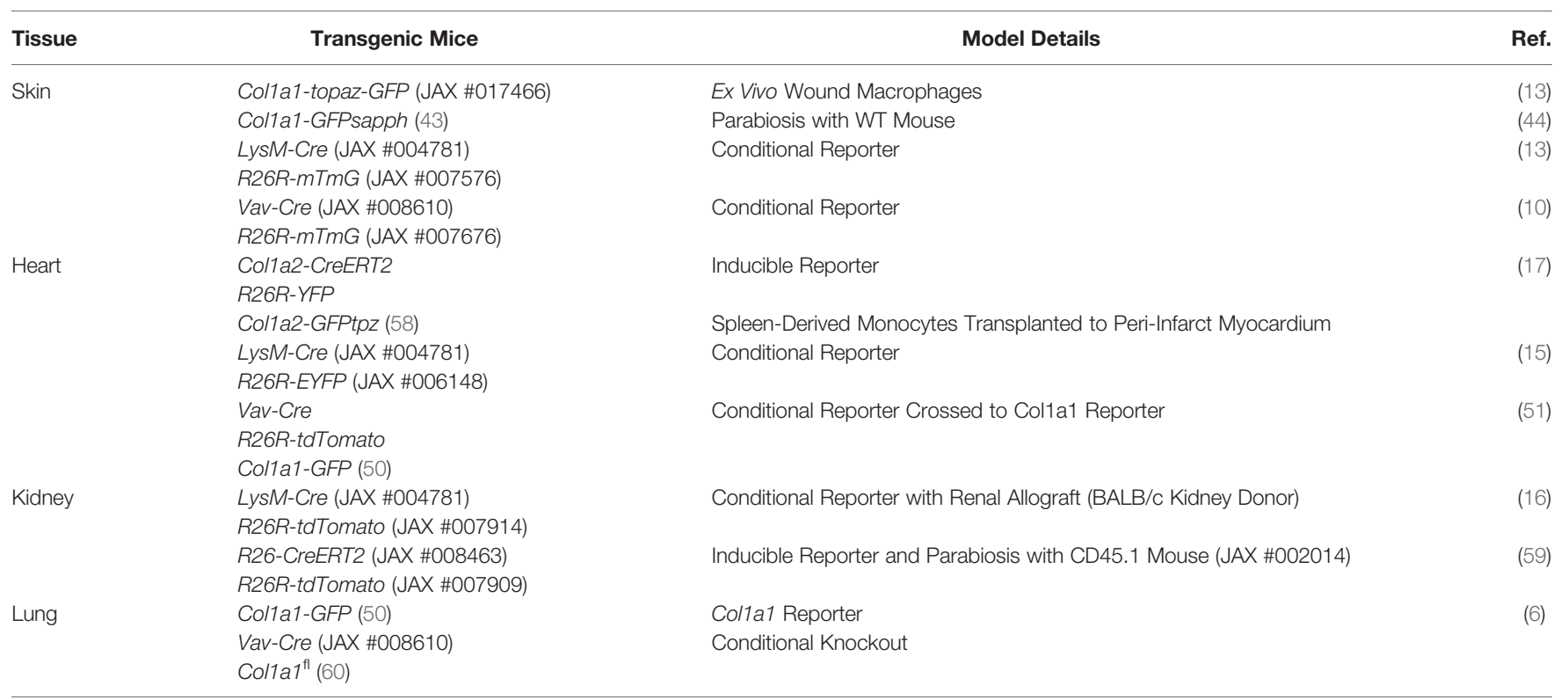

WT, wild type (C57BL/6); JAX, Jackson Laboratories. 
6 weeks after transplantation with some expressing the myofibroblast marker $\alpha$ SMA. A strategy that can alleviate potential concerns associated with the engraftment of BMMSCs throughout the body is to perform sorting to enrich the CD45+ or HSC fractions of BM prior to transplantation. This has been accomplished successfully with mice surviving and reaching high levels of peripheral blood chimerism with greater than $90 \%$ of circulating cells being donor-derived (5).

\subsubsection{Ubiquitous Donor BM Cell Labeling}

Bleomycin-induced lung fibrosis was performed in chimeric mice generated by transplanting BM from GFP donors into lethally irradiated wild type (WT) recipients. Flow cytometry performed on disaggregated cells from lung tissue found $27.5 \%$ of cells expressed GFP and were Col1+, representing $80 \%$ of Col1+ cells (11). When GFP+ cells isolated from lung tissue were cultured, these cells adopted a spindle-shaped, fibroblast morphology, however none expressed the myofibroblast marker $\alpha$ SMA and they were resistant to TGF- $\beta 1$-induced myofibroblast differentiation. In a myocardial infarction (MI) model of heart fibrosis, coronary artery ligation was performed on chimeric mice generated by transplanting BM from enhanced GFP (EGFP) mice into lethally irradiated WT recipients (12). At day 7 post-MI, BMderived $\alpha \mathrm{SMA}+$ cells peaked, averaging $21 \%$ of BM-derived cells and $24 \%$ of $\alpha \mathrm{SMA}+$ cells. In another study using a similar chimeric mouse model, following coronary artery ligation 57\% of myofibroblasts (vimentin $+\alpha \mathrm{SMA}+$ ) were BM-derived (48). In addition to the difference in how fibrocyte-derived myofibroblasts were identified, a noticeable difference between the two studies that might account for the difference in the percentage of BMderived myofibroblasts is that the latter study transfused 3-5-fold more donor BM cells into recipient mice. In a splinted dermal excisional wound healing model, BM-derived cells were tracked using chimeric mice generated by transplanting BM from EGFP donors into lethally irradiated WT recipients (13). At day 5, multicolor immunofluorescence identified EGFP+ F4/80+ Coll + cells within the wound.

\subsubsection{Lineage Tracing}

Vav-1 is a pan-hematopoietic marker expressed almost exclusively in hematopoietic cells $(10,69)$. Vav-1 has advantages over CD45, regarded as the most specific marker for hematopoietic cells, because CD45 is expressed during later stages of hematopoietic progenitor cell development and incompletely identifies hematopoietic-derived cells (70). Transgenic Vav-Cre x R26R-mTmG mice have been used to identify fibrocytes in a dermal excisional wound model (10). In $m T m G$ mice, cells express membrane-targeted tandem dimer Tomato (tdTomato), a red fluorescent protein (RFP), prior to Cre-mediated excision and membrane-targeted GFP after excision. In Vav-Cre $x$ R26R-mTmG mice, nearly all peripheral blood cells were GFP+ and circulating RFP+ cells were not detected. Single-cell qPCR performed on cells isolated from the wound identified expression of Col1a1, Col1a2, and Col3a1 by monocytes and macrophages that peaked at day 7 post wounding. Of these cells, 5\% had low expression of CD 45 and
$60 \%$ had low expression of CD11b showing that use of these markers would have under identified fibrocytes. Another study employing a lung fibrosis model selectively knocked out production of Coll in hematopoietic-derived cells by using Vav-Cre x Colla1 ${ }^{f l}$ mice (6). Fibrocytes with confirmed deletion of the Colla1 gene still immunolabeled for Col1, lending further support that positive immunolabeling for Coll is not reliable strategy for identifying fibrocytes as it does not discriminate Coll expression from uptake of Coll from the surrounding environment. An important detail to consider when interpreting these findings is that the antibody used in this study was polyclonal, generated using Coll as the antigen, and may exhibit reactivity with pColla2. Therefore, positive immunolabeling by this Coll antibody may not definitively identify uptake of collagen in cells lacking the ability to express Colla1 but retaining the ability to express Colla2.

$\mathrm{CD} 11 \mathrm{~b}$ is expressed on fibrocytes, monocytes, granulocytes, and NK cells; therefore, CD11b is more selective for fibrocytes than pan-hematopoietic labeling based on Vav-1 or CD45 expression. However, while CD11b is expressed on a majority of these cells its expression is not ubiquitous so this is not regarded as an efficient marker. In a unilateral ureteral obstruction (UUO) model of kidney fibrosis, ablation of CD11b expressing cells was performed using CD11b-DTR mice (14). In these mice, expression of the diphtheria toxin receptor (DTR) is under the control of the CD11b promotor and administration of diphtheria toxin (DT) results in depletion of $\mathrm{CD} 11 \mathrm{~b}+$ cells. Chimeric mice were generated by transplanting BM from CD11b-DTR donors into lethally irradiated WT recipients. These chimeras allow for selective depletion of CD11b expressing BM-derived cells and not other BM-derived cells or host cells that express CD11b. A single injection of DT reduced peripheral blood monocytes by $\sim 50 \%$ and subsequent injections almost completely depleted monocytes in the blood and obstructed kidney. Following monocyte depletion, in the spleen Col1+ fibrocytes were reduced by nearly two-thirds and in the obstructed kidney Col1+ fibrocytes were depleted or infiltration had been impaired.

Lysozyme M (LysM) is expressed on monocytes, macrophages, and granulocytes. Assuming granulocytes maintain their unique surface marker expression, they can be distinguished from monocytes and macrophages by immunolabeling, such as for expression of myeloperoxidase by neutrophils (13). Coronary artery ligation-induced MI was performed in LysM-Cre x R26R-EYFP mice that use enhanced yellow fluorescent protein (EYFP) as the reporter and remodeling of the infarct was tracked for 6 weeks (15). LysMderived cells in the infarct region possessed a round morphology at 1 week and some possessed an elongated morphology at 6 weeks. LysM-derived Col1+ cells were observed at 1 week and Col1 immunolabeling appeared relatively more intense at 6 weeks. A separate study used similar LysM lineage reporter mice in a renal allograft model of chronic rejection in which $\mathrm{BALB} / \mathrm{c}$ kidneys were transplanted into LysM-Cre $\mathrm{x}$ R26RtdTomato recipient mice (16). At the 28 day endpoint, in the donor kidney most F4/80+ macrophages were tdTomato+ host- 
derived cells and many of these were Col1+ $\alpha \mathrm{SMA}+$. The translational relevance of these findings was demonstrated in biopsies performed on human renal allografts. Immediately following transplantation, no cells co-expressed the macrophage marker CD68 and $\alpha$ SMA. In acute renal allograft rejection, there was a greater number of $\mathrm{CD} 68+$ macrophages and a few expressed $\alpha$ SMA. However, in chronic renal allograft rejection there were many $\alpha \mathrm{SMA}+$ cells in regions with severe interstitial fibrosis, half expressed CD68, and some were Col1+. A caveat with these findings is that the choice to identify fibrocytes by CD68 and $\alpha \mathrm{SMA}$ expression might be misleading as during wound healing SMCs that normally express $\alpha \mathrm{SMA}$ may also express macrophage markers including CD68 and Mac$3(71,72)$. A different study used $L y s M$-Cre x R26R-mTmG mice to characterize fibrocytes in a murine splinted excisional wound model (13). LysM-derived cells isolated from the wound edge by laser capture microdissection expressed Colla1 at days 3 and 7 post wounding as determined by qPCR.

Since by definition fibrocytes must produce collagen, a complementary strategy to those previously mentioned for identifying fibrocytes is to use a reporter of collagen expression (e.g., Colla1-GFP) and identify labeled cells that also express a hematopoietic marker $(12,46)$. This approach circumvents concerns regarding the use of Coll immunolabeling to identify fibrocytes. In a cardiac fibrosis model, coronary artery ligation was performed on chimeric mice generated by transplanting BM from Col1a1-GFP donors into lethally irradiated WT recipients (51). In response to coronary artery ligation or placement of a suture in sham mice, GFP+ cells that co-expressed CD45 and possessed a round morphology were observed at the pericardial surface, but not within the infarcted myocardium. The hematopoietic origin of these cells was confirmed following coronary artery ligation in Vav-Cre $\mathrm{x} R 26 R$-tdTomato $\mathrm{x}$ Colla1-GFP mice as these GFP+ cells were also tdTomato+. In a UUO kidney fibrosis model, chimeric mice were generated by transplanting BM from Col1a1-GFP donors into lethally irradiated WT recipients (53). A small number of GFP+ CD34+ CD45+ cells were detected exclusively in perivascular areas and were typically found surrounding venules in fibrotic kidneys, but BM-derived cells were not found in normal kidneys or the contralateral unobstructed kidney. However, GFP+ cells accounted for only 1 out of every 1000 Colla 1 expressing cells. In a bile-duct ligation induced liver injury model, chimeric mice were generated by transplanting BM from Colla1-GFP donors into lethally irradiated WT recipients. BM-derived cells localized to the site of injury and represented $\sim 5-10 \%$ of Collal expressing cells (54). In a splinted dermal excisional wound healing model, Colla1 expression by wound macrophages was discovered to be induced by keratinocyte-derived miR-21 (13). Macrophages isolated from dermal wounds of Col1a1-(topaz-GFP) mice at day 3 were treated with a miR-21 mimic and showed several-fold greater expression of GFP compared to treatment with nonspecific miR. Keratinocyte stimulated collagen production demonstrates tissue-specific signaling pathways may enable certain tissues an advantage over other tissues at promoting collagen production by hematopoietic cells.
In a recent study, to determine whether monocytes and macrophages directly participate in scar formation following MI, coronary artery ligation was performed on Colla2-CreERT2 $\mathrm{x} R 26 R-Y F P$ mice at postnatal day 7 (P7) and Cre was activated at day 5 post-MI (17). Multicolor immunofluorescence identified CD68+ macrophages that were YFP+, however analysis of the single color image for the YFP channel on the representative image showed that YFP expression in CD68+ cells was weak relative to YFP+CD68- cells and YFP signal was detected in only a fraction of the cell area immunofluorescent for CD68. In this transgenic mouse model, Cre-mediated recombination should result in stable expression of YFP. Weak YFP expression in CD68 + cells relative to CD68- cells raises the question as to whether the CD68+ cells are truly expressing YFP or whether the YFP fluorescence signal in CD68+ cells might have other explanations that might include autofluorescence, which is a feature of heart tissue, a YFP+ CD68- cell and a YFP- CD68+ cell slightly out of plane with each other, or phagocytosis of apoptotic YFP+ cells by CD68+ cells.

In separate experiments within the same study, to determine whether monocyte-derived cells produce collagen that contributes to scar formation post coronary artery ligation, donor splenic monocytes from Colla2-GFPtpz mice that express a collagen-GFP fusion protein were enriched by immunomagnetic negative selection and injected into the peri-infarct myocardium of adult WT mice at the time of coronary artery ligation. At day 7 post-MI, within the scar region GFP signal colocalized almost exclusively with CD68+ cells, though not all CD68+ cells colocalized with GFP. The latter reflects CD68+ cells of donor origin that were not producing collagen and CD68+ cells of host origin regardless of collagen expression. Given that macrophages can take up collagen, the GFP+ CD68+ population may include non-collagen producing cells of donor or host origin that had recently internalized GFP labeled collagen. At day 21 post-MI, Coll immunolabeling was highly coincident with the GFP signal. To state this differently, it appeared as though nearly all Coll fibers contained the collagen-GFP fusion protein. In the absence of donor monocyte injection $75 \%$ of Collal expressing cells in the heart following coronary artery ligation were identified as fibroblasts compared to $5.5 \%$ of Colla1 expressing cells identified as macrophages. While the intramyocardial injection of splenic monocytes would be expected to result in a localized region containing an artificially high Col1a2-GFPtpz donor monocyte to host WT fibroblast ratio, the apparent lack Col1 fibers not containing collagen-GFP remains a bit surprising. A challenge when performing immunofluorescence on collagen containing tissue is autofluorescence of collagen. While the authors attempted to address this potential issue by immunolabeling GFP and Col1, the representative images presented call into question whether these efforts were sufficient to avoid this phenomenon. An unaddressed concern that could impact the findings of this study as well as others using transgenic mice expressing a collagen-GFP fusion protein is the potential immunogenicity of GFP. GFP is a foreign protein and the immune response to GFP may enhance macrophage uptake of collagen fibers containing the collagen-GFP fusion protein (73). 


\subsubsection{Parabiosis}

Parabiosis is the surgical joining of two organisms which results in a shared circulatory system. An advantage of parabiosis models over chimeric mice is that one need not be concerned with potential engraftment of MSCs in tissues throughout the body or trauma as a result of irradiation. A modest disadvantage is that chimerism results in a 50:50 representation of cells from each parabiont within the blood. To look at the contribution of circulating fibrocyte-derived myofibroblasts in UUO model of kidney fibrosis, one study used a parabiosis model in which the parabiont to later undergo kidney fibrosis possessed the CD45.1 isoform and the other parabiont was R26-CreERT2 x R26RtdTomato x CD45.2 (59). In the latter parabiont, CreERT2 is constitutively expressed in all cells and tamoxifen administration should result in tdTomato expression. Therefore, cells from this parabiont should be distinguishable by both CD45.2 and tdTomato expression. Ten days following UUO surgery, more than half of CD45+ cells in the UUO kidneys were derived from CD45.2 parabiont and tdTomato+ cells accounted for $10 \%$ of $\alpha \mathrm{SMA}+$ cells. A different study sought to determine if BMderived fibrocytes contribute to excisional dermal wound healing by using a parabiosis model in which the parabiont to receive the dermal wound was WT and the other parabiont possessed the Col1a1-GFP transgene (44). Only a few GFP+ cells could be detected in the wound of the non-transgenic parabiont. GFP+ cells possessed a wide range in morphology from round to spindle-shaped and some expressed Mac-3, but an acknowledged caveat is that the expression of the visual Col1a1-GFP transgene that was used for cell identification in this study may not always correlate with endogenous Colla1 gene expression within myeloid cells.

\subsubsection{Transcriptional Analysis}

In studies of fibrocytes, transcriptional analyses have traditionally relied on $\mathrm{qPCR}$ which quantifies the amount of known sequences of RNA relative to a reference gene. Compared to $\mathrm{qPCR}$ performed on a mixed population of cells isolated from whole tissue, more insightful data is generated when qPCR is performed on purified populations or even single cells. In contrast, next generation sequencing methods such as RNASeq enable quantification of gene expression without requiring prior knowledge of sequence information thereby allowing for a broader, unbiased assessment of gene expression. scRNA-Seq is particularly revealing as it aids in cell phenotyping and enables the assessment of heterogeneity within cell subpopulations. As costs come down and accessibility to next generation sequencing methods increases, single-cell transcriptional analyses are increasingly being employed that promise to accelerate our collective understanding of fibrocytes.

In a coronary artery ligation model performed in Colla1-GFP mice, 7 days following MI bulk RNA-Seq was performed on macrophages isolated from hearts and enriched by flow assisted cell sorting (17). Compared to mice in which ligation was performed at postnatal day 1 (P1), when ligation was performed at $\mathrm{P} 7$, in macrophages there was upregulation of Col1a1, Col1a2, and Col3a1 as well as additional ECM genes including Col8a1, Col5a2, Col6a2, Fbn1, Postn, and Bgn. Gene expression was not measured in a reference cell type, such as a cardiac fibroblast, so no comparison can be made as to gauge relative collagen production by these cardiac macrophages. In a separate study, scRNA-Seq was performed on cells from a mouse non-splinted excisional wound model 12 days post wounding (5). Myeloid-derived cells represented $15 \%$ of all cells within the wound and myofibroblasts expressing LysM, Col12a1, and the contractile markers $\alpha S M A$ and SM22 represented $\sim 11 \%$ of all wound fibroblasts. Pseudotime analysis showed the conversion of LysM expressing myeloid cells into fibroblasts. Using SM22Cre x R26R-tdTomato mice, single-cell western blot confirmed that $6 \%$ of SM22 expressing cells were LYZ+. Immunostaining further confirmed the presence of LYZ+ $\alpha \mathrm{SMA}+$ cells within wounds. scRNA-Seq performed on cells isolated from 15 and 21 day wounds showed that a population of fibrocyte-derived myofibroblasts persisted within wounds. The possibility that cell fusion of BM-derived cells and fibroblasts could account for the apparent generation of BM-derived fibrocytes was ruled out in chimeric mice generated by transplanting GFP+ HSCs into lethally irradiated RFP+ recipients. While cells expressing both GFP and RFP were observed, their presence was rare within wounds. However, this experiment did not address potential fibrocyte generation by fusion of a radioresistant, tissue resident macrophage with a fibroblast.

\subsection{Collagen Production by Fibrocytes}

Few studies have attempted to determine the amount of collagen produced by fibrocytes relative to overall collagen production during fibrosis. In vitro, cultured pulmonary fibroblasts expressed 13-fold greater Colla1 and 34-fold greater Col3a1 mRNA on a per cell basis than PBMC-derived fibrocytes (2). Correspondingly, significantly greater collagenous protein was produced by cultured pulmonary fibroblasts than PBMC-derived fibrocytes. Human PBMC-derived fibrocytes from normal subjects and burn patients produced substantially less hydroxyproline in vitro than dermal fibroblasts and weakly expressed pCollal on a per cell basis compared to cultured normal human dermal fibroblasts $(18,74)$. Regarding the relevance of in vitro experiments to collagen expression by fibrocytes in vivo, a different study compared the expression of Colla1 mRNA from CD45+ cells isolated from a human dermal wound at 1 week to human fibrocytes differentiated from PBMCs for 10 days and found comparable expression (7).

In vivo, collagen production by fibrocytes has been investigated in dermal wound and fibrosis models in Colla2luciferase mice. Non-splinted dermal excisional wounds were performed on these transgenic mice as well as chimeric mice generated by transplanting BM from Colla2-luciferase donors into lethally irradiated WT recipients (46). Luciferase activity was almost non-existent in chimeric mice compared to Colla2luciferase mice indicating that BM-derived cells do not directly contribute significant collagen production to healing dermal wounds. In a separate experiment, bleomycin-induced dermal fibrosis was performed on chimeric mice generated by transplanting BM from Col1a2-EGFP donors into lethally irradiated WT recipients. 21 days after induction, the fibrotic tissue contained spindle-shaped and round EGFP+ cells that 
represented $\sim 5 \%$ of Colla 2 producing cells, though the relative amount of collagen produced by BM-derived cells compared to non-BM-derived cells was not determined.

In a splinted dermal excisional wound healing model, deletion of miR-21 in keratinocytes resulted in a decrease in Col1+ macrophages at the wound site, deficiency in wound granulation tissue collagen content, and decreased stiffness of the repaired skin (13). However, the relative number of fibrocytes to total collagen producing cells was not quantified nor was the effect of miR-21 on non-fibrocyte collagen producing cells. Therefore, it is unclear how significant collagen produced by macrophage-derived fibrocytes is to overall collagen produced within a healing dermal wound. In addition, splinting results in increased tension in the healing wound which may increase fibrosis (75). The effect of splinting on fibrocyte differentiation and collagen production by fibrocytes was not compared to nonsplinted wounds, so it is not apparent how relevant collagen production by fibrocytes in splinted wounds is to the more physiological setting of dermal wound healing.

In a coronary artery ligation model performed on Colla1GFP mice, flow cytometry was used to characterize cells isolated from the heart at day 7 post MI (17). F4/80+ macrophages comprised $0.45 \%$ of total cells compared to $6.1 \%$ for fibroblasts, but $46.2 \%$ of F $4 / 80+$ cells were GFP+ compared to just $22.5 \%$ of fibroblasts. Overall, F4/80+ cells accounted for $6.8 \%$ of GFP+ cells. Following up on these observations, BM-derived macrophages from Colla2-GFPtpz mice expressing a GFPtpzcollagen fusion protein were co-cultured with L929 fibroblasts. GFP+ collagen fibers could be seen in close proximity to CD68+ macrophages. The high resolution confocal images of a single macrophage revealed a punctate staining pattern for CD68 and GFP consistent with intracellular vesicles. If this cell was producing collagen, then the GFP signal should be associated with secretory vesicles. CD68, also known as lysosome associated membrane protein 4 (LAMP4), is often associated with the endosomal/lysosomal compartment. While nearly all CD68+ immunolabeling overlapped with GFP, there were regions of GFP signal absent for CD68 immunolabeling. This pattern of staining raises the question as to whether this GFP labeled collagen is being secreted and/or degraded by the single macrophage imaged. For this experiment, BM-derived macrophages were isolated by plating BM cells and selecting for adherent cells after 7 days of culture. This is similar to the procedure of isolating fibrocytes from the blood which involves density gradient centrifugation, plating of cells from the buffy coat to select for adherence, and culture for up to 14 days in serum containing medium to enrich for cells that have an elongated morphology (30, 76). Unlike PBMCs, BM cells contain fibroblasts which are also adherent cells and no characterization was reported to validate the purity of these BM-derived macrophages. Therefore, the concern raised by the details provided is that the BM-derived macrophages may have been contaminated with fibroblasts, collagen fibrils observed may have been produced by these contaminating fibroblasts, and the macrophage pictured may have been in the process of degrading and taking up this collagen, not producing it.
After observing that fibrocytes produced less collagen than dermal fibroblasts, as measured by a hydroxyproline assay, one study sought to characterize the indirect role of fibrocytes on collagen production by dermal fibroblasts (18). Cultured dermal fibroblasts were treated with conditioned medium from cultured fibrocytes derived from the peripheral blood. Fibrocyte conditioned medium from burn patients, but not from normal subjects, increased fibroblast proliferation and migration, $\alpha$ SMA expression, and contraction of collagen gels. These effects were determined to be caused by elevated TGF- $\beta 1$ in conditioned medium from burn patient fibrocytes that could be counteracted by using a TGF- $\beta 1$ neutralizing antibody.

The consensus appears to be that fibrocytes make up a small percentage of collagen producing cells and that on a per cell basis fibrocytes produce far less collagen than fibrogenic cells to which they have been compared. Not to dismiss the direct contribution of fibrocytes to fibrosis, but it seems that fibrocytes as well as monocytes and macrophages from which fibrocytes may be derived have a greater indirect role on fibrosis. These hematopoietic-derived cells produce growth factors and cytokines that stimulate recruitment, proliferation, matrix production, and myofibroblastic differentiation by traditional fibrogenic cells in addition to stimulating their own fibrocyte differentiation in an autocrine manner (77, 78). Systemic depletion of monocytes and macrophages significantly reduces tissue fibrosis, a finding that appears independent of fibrocyte activity $(14,79)$. Therefore, antifibrotic strategies that target monocytes and macrophages upstream of fibrocyte differentiation might be more effective, analogous to killing two birds with one stone.

\subsection{Fibrocyte-Derived Myofibroblasts}

To properly evaluate studies reporting fibrocyte-derived myofibroblasts, one must first understand the criteria for a cell to be identified as a myofibroblast. Tomasek et al. described a two-stage model of myofibroblast differentiation from fibroblasts (80). Growth factors released during the early stages of wound healing activate fibroblasts, stimulate their migration toward the site of injury, and induce the expression of the ED-A splice variant of fibronectin. As fibroblasts begin to reorganize the collagen matrix by exerting traction forces, they develop cytoplasmic beta- and gamma-actin containing stress fibers and upregulate expression of ED-A fibronectin. Subsequent exposure to TGF- $\beta 1$ in the sustained presence of ED-A fibronectin and mechanical stress promotes the expression of $\alpha \mathrm{SMA}$, stress fiber development, expansion adhesion complexes, as well as increases the production of ECM proteins, features that collectively establish the myofibroblast phenotype. The presence of $\alpha$ SMA is significant because it enables cells to generate greater contractile force than non- $\alpha$ SMA expressing cells and is a feature that grants myofibroblasts the prefix "myo" to denote that these cells are "smooth-muscle-like" $(80,81)$.

Though the myofibroblast phenotype is defined by multiple distinctive features, $\alpha \mathrm{SMA}$ is a commonly accepted marker for identifying fibroblast-derived myofibroblasts. Using $\alpha \mathrm{SMA}$ expression to identify fibrocytes or myofibroblasts derived 
from hematopoietic cells is relatively more problematic because it presumes collagen expression and this is not a safe assumption; in situ hybridization performed on heart tissue in a coronary artery ligation model found that $30 \%$ of $\alpha$ SMA expressing cells did not express Colla1 (82). In the absence of demonstrated collagen expression, it would arguably be more accurate to refer to $\alpha$ SMA+ hematopoietic-derived cells by the protologism myohematopoietic cells, or perhaps more specifically as myomyeloid cells. However, so as to not introduce potential confusion, $\alpha S M A+$ hematopoietic-derived cells will be referred to as $\alpha \mathrm{SMA}+$ or as myofibroblasts in keeping with the nomenclature from the cited source.

Fibrocyte-derived myofibroblasts have been generated and studied in vitro. Freshly isolated human PBMCs did not express $\alpha \mathrm{SMA}$, as determined by qPCR, but $\alpha \mathrm{SMA}$ mRNA was detected after 10 days in culture (20). Expression increased 4-fold and kinetics of expression could be increased when the culture medium was supplemented with TGF- $\beta 1$ (20, 22). Another study reported that in cultures of Col1 + CD34+ cells isolated from the peripheral blood, after 6 days in serum free medium $20 \%$ expressed $\alpha$ SMA, but more than $80 \%$ expressed $\alpha$ SMA in the presence of TGF- $\beta 1$ (9). The contractile ability of $\alpha \mathrm{SMA}+$ fibrocytes has been assessed by suspending cells within a collagen gel (20). After 72 hours, PBMCs contracted gels by $\sim 5 \%$ compared to $\sim 20 \%$ for cultured fibrocytes, $\sim 30 \%$ for fibrocytes cultured in the presence of TGF- $\beta 1$, and $40 \%$ for dermal fibroblasts. Unlike fibrocyte collagen production, which has been measured to be far below that of dermal fibroblasts, based on this one study collagen gel contraction appears relatively similar between fibrocytes and fibroblasts. In future studies of fibrocyte-derived myofibroblasts, perhaps greater emphasis should be placed on their contribution to contraction-mediated ECM remodeling than collagen production.

In vivo, the presence of BM-derived cells expressing $\alpha \mathrm{SMA}$ appeared to be dependent on the tissue and/or the model used. Flow cytometry showed that in healthy humans a small minority of circulating Col1+ CD45+ fibrocytes were positive for $\alpha \mathrm{SMA}$ with no significant difference observed in patients with interstitial pneumonia (21). In $\alpha S M A-G F P$ mice, $0.15 \%$ of circulating mononuclear cells were GFP+, although the average intensity of GFP was far lower than in aortic smooth muscle cells from the same transgenic mice indicating lower $\alpha \mathrm{SMA}$ expression (56). A detail to consider when interpreting these findings is that the half-life of unmodified GFP in mammalian cells is reported to be $\sim 26 \mathrm{hrs}$, so circulating cells may have stopped translating $\alpha$ SMA protein days ago (83). In a lung allergic asthma model induced by ovalbumin, 24 hours following intravenous administration of labeled fibrocytes $\alpha$ SMA expression had increased in labeled cells isolated from lung tissue (9). In the heart, following coronary artery ligation $\alpha$ SMA was detected in BM-derived cells and in Colla2-derived BM cells, but not among LysM-derived BM cells $(12,15,48)$. In kidney fibrosis studies, one study did not find $\alpha$ SMA expression on Colla1-derived BM cells, a second study using a parabiosis model found that $10 \%$ of $\alpha \mathrm{SMA}+$ cells could be identified as originating from the parabiont, and a third study found that $35 \%$ of $\alpha \mathrm{SMA}+$ cells were BM-derived, but did not confirm collagen production by these cells $(52,53,59)$. The contribution of BMderived cells to neointimal and medial cells in vascular injury models was investigated in chimeric mice generated by transplanting CAG-GFP BM into lethally irradiated WT recipients (57). In response to wire-induced injury, many BMderived GFP+ cells in the intima and media expressed $\alpha \mathrm{SMA}$, but few expressed $\alpha$ SMA in response to cuff- or ligation-induced injury. In a bile-duct ligation induced liver injury model, chimeric mice were generated by transplanting BM from Col1a1-GFP donors into lethally irradiated WT recipients. BMderived cells localized to the site of injury and represented $\sim 5$ $10 \%$ of Colla1 expressing cells, but did not express $\alpha$ SMA (54). In a bleomycin-induced dermal fibrosis model performed on chimeric mice generated by transplanting BM from Col1a2EGFP mice into lethally irradiated WT recipients, $\alpha$ SMA was expressed in a small number of the EGFP+ semi-round cells, but not in most of the spindle-shaped cells (46).

Conflicting findings regarding the presence of $\alpha \mathrm{SMA}+\mathrm{BM}$ derived cells have been reported in dermal wound and fibrosis models. In a splinted dermal excisional wound model performed in Vav-Cre x R26R-mTmG mice, 7 days following wounding many $V a v$-derived cells expressed $\alpha$ SMA, but nearly all cells possessed a round morphology (10). After 14 and 28 days, $\alpha$ SMA expression on hematopoietic-derived cells had diminished compared to day 7 . Though collagen production in hematopoietic-derived cells expressing $\alpha$ SMA was not demonstrated in vivo, qPCR performed on primary cultures of $\mathrm{BM}$-derived CD11b+ cells showed that TGF- $\beta 1$ increased the expression of both Coll and $\alpha$ SMA. In addition, single cell qPCR performed on monocytes and macrophages isolated from dermal wounds at day 7 and bulk qPCR performed on cultured CD11b+ cells showed the production of Coll by these cells. In contrast to these findings, in a non-splinted dermal excisional wound model performed on chimeric mice generated by transplanting BM from Col1a2-EGFP donors into lethally irradiated WT recipients, the number of EGFP+ cells peaked at day 7, but no EGFP+ cells expressed $\alpha$ SMA (46). Similar findings were reported in a parabiosis model in which the parabiont to receive a nonsplinted excisional dermal wound was WT and the other parabiont possessed the Col1a1-GFP transgene (44). Only a few GFP+ cells could be detected in the wound of the nontransgenic parabiont and all GFP+ cells were negative for $\alpha$ SMA. The presence of $\mathrm{BM}$-derived $\alpha \mathrm{SMA}+$ cells in the splinted wounds but not non-splinted wounds may be explained by the increased mechanical tension present in the splinted wound, a factor recognized to promote $\alpha$ SMA expression and myofibroblast differentiation (75). Alternatively, if the difference in $\alpha S M A$ expression was simply due to the different transgenic mouse models, it is possible that $\alpha \mathrm{SMA}$ expression was similar between splinted and non-splinted wounds, but that $\alpha$ SMA was not observed in BM-derived cells in the non-splinted wounds because it was expressed in the fraction of BM-derived cells not expressing Colla1 or Colla2.

PDGFR $\beta$ is another marker that has been used to identify fibrocyte-derived myofibroblasts (59). In a UUO model of kidney 
fibrosis, circulating "hematopoietic-derived myofibroblasts" were identified as PDGFR $\beta+\mathrm{CD} 45+$ and non-hematopoietic tissue resident cells as PDGFR $\beta+$ CD45-. The justification for using PDGFR $\beta$ to identify myofibroblasts was that this marker has been reported to be expressed on myofibroblasts and circulating fibrocytes. However, it was not addressed whether non-myofibroblasts present in the UUO kidney or circulation might also express PDGFR $\beta$. Therefore, while PDGFR $\beta$ may have a high sensitivity for identifying myofibroblasts, its specificity, or the rate of false positives was not presented. Accordingly, scRNA-Seq performed on these two populations showed that gene expression of hematopoietic-derived, PDGFR $\beta+$ CD $45+$ cells correlated strongly with human peripheral blood monocytes and the expression of matrix genes and $\alpha \mathrm{SMA}$ was low compared to tissue resident-derived, PDGFR $\beta+$ CD45- cells. While circulation-derived cells provided a small contribution to the population of myofibroblasts, they were found to express a relatively high amount of chemokines and interleukins indicating they may have a greater indirect role in regulating kidney fibrosis by secreting paracrine factors.

\subsection{Potential Origins of Fibrocytes}

In healthy animals, at the time of isolation $\sim 1 \%$ of PBMCs were Col1 $+\mathrm{CD} 34+$ giving the appearance circulating fibrocytes were already differentiated or partially differentiated cells $(9,14,84,85)$. Coll + CD $45+$ cells can also be found in the $\mathrm{BM}$ of healthy mice suggesting that perhaps fibrocytes differentiate prior to entering the circulation $(24,25)$. However, it remains to be determined whether fibrocytes might differentiate from a distinct fibrocyte precursor or from myeloid cells (e.g., monocytes) within the BM. Regarding the latter possibility, in the original study that identified fibrocytes, fibrocytes isolated from the wound chamber assay appeared distinct from monocytes because they lacked expression of CD14 and non-specific esterases. This should not be interpreted to exclude monocytes as a potential origin for fibrocytes. In fact, a 20-year follow-up article by the first author of the foundational study recognized that fibrocytes arise from circulating monocyte precursors (86). Also, a 2001 study found that in vitro fibrocytes could only be differentiated from the peripheral blood $\mathrm{CD} 14+$ mononuclear cell population and not CD14- population; CD14 expression was lost during differentiation of fibrocytes $(20,32,87)$. The ability to differentiate fibrocytes from the CD14+ fraction of PBMCs in vitro may indicate that fibrocytes are derived from monocytes, but another possibility is that monocytes and distinct fibrocyte precursors simply share surface expression of this marker. Absence of CD14 expression on fibrocytes might instead be better considered as an indication of the extent of fibrocyte differentiation. In addition, for cultured cells prolonged exposure to the artificial environment and high concentrations of growth factors present in tissue culture is known to cause genetic and epigenetic alterations may override inherent potential and cell-autonomous fate decisions, inflating differentiation potential (76). As applied to cultured PBMCs, a blood-derived cell that becomes a fibrocyte in culture may not have possessed the potential to do so in response to natural cues in vivo. Thus, a culture-enriched population of fibrocytes may misrepresent the origin and phenotype of the in vivo fibrocyte population.

Fibrocyte differentiation from monocytes and macrophages has been investigated in vivo. In a coronary artery ligation model of MI, in situ hybridization performed 7 days following ligation found $47 \%$ of EMR1 (i.e., gene for F4/80) expressing macrophages also expressed Colla1 and 26\% co-expressed Colla1 and the myofibroblast marker Postn (82). One quarter of EMR1+ cells, expressed the monocyte marker Ccr2 suggesting these macrophages were derived from newly infiltrated monocytes, however none of these monocyte-derived macrophages expressed Colla1 or Postn. This suggests that in this particular model if newly infiltrated monocytes differentiate into fibrocytes they must first pass through an intermediate phenotype (e.g., macrophage) with loss of Ccr2 expression. A hematopoietic-derived EMR1- population was not characterized, therefore it cannot be concluded whether monocytes may differentiate into fibrocytes without transitioning through and $E M R 1+$ macrophage-like intermediate. In addition, identifying macrophages by EMR1 expression does not distinguish monocyte-derived macrophages from tissue resident macrophages, so this study was not designed to determine whether one of these populations might have a greater propensity for differentiating into fibrocytes.

The effect of depleting potential BM-derived myeloid precursors of fibrocytes has been investigated in a unilateral ureteral obstruction (UUO) model of kidney fibrosis performed in chimeric mice generated by transplanting BM from CD11b$D T R$ donors into lethally irradiated WT recipients (14). In these transgenic mice, expression of the diphtheria toxin receptor (DTR) is under the control of the CD11b promotor and administration of diphtheria toxin (DT) results in depletion of CD11b expressing cells. BM chimeras allow for selective depletion of $C D 11 b$ expressing BM-derived cells and not other BM-derived cells or host cells that express CD11b. A single injection of DT reduced peripheral blood monocytes by 50\% and subsequent injections almost completely depleted monocytes in the blood and obstructed kidney. Following monocyte depletion, in the obstructed kidney Col1+ CD45+ fibrocytes were reduced compared to mice not treated with DT. One interpretation is that circulating fibrocytes and/or fibrocyte precursors were depleted, or that infiltration into the kidney had been impaired. However, CD11b is not specific for fibrocyte precursors and myeloid cells expressing CD11b are a source of cytokines and growth factors that may stimulate the differentiation of tissue resident macrophages into fibrocytes or the activation of tissue resident fibrocyte precursors. Thus, this model does not allow for determining whether fibrocytes originate from circulating BM-derived cells or from non-BMderived fibrocyte precursors already present within the kidney.

The prior examples demonstrate that, by focusing on BMderived cells, BM chimera and parabiosis models may fail to identify fibrocytes derived from hematopoietic-derived cells preexisting within tissues and therefore provide an incomplete 
picture of the contribution of fibrocytes to fibrosis. Few studies address "other tissue sources", as suggested as a possible origin in the study that first identified fibrocytes (4). It may be that having named these cells fibrocytes because they produce collagen (fibro) and may be derived from the circulation (cyte), in addition to the common practice of isolating fibrocytes from PBMCs, creates the potential to mistakenly interpret that all fibrocytes must be recently derived from the circulation. Hematopoietic-derived cells established early during development exist in tissues throughout the body with varying rates of replenishment from the BM (88). If one were to design studies based on a broader interpretation that includes hematopoietic-derived cells regardless of their timing or journey from genesis during hematopoiesis to presence within a tissue, one could achieve a more comprehensive understanding of the origin or origins of fibrocytes. As an example, one source of a potential fibrocytes that would be included under this broader interpretation of hematopoietic-derived cells are peritoneal macrophages that can produce collagen in culture $(89,90)$.

Perhaps contributing to this potential confusion is that cultured fibrocytes express CD34, also called HSC antigen. Expression of this hematopoietic marker with isolation of fibrocytes from PBMCs suggests that HSCs in the BM may be a source fibrocytes. What is then easy to overlook is that while BM could be "a" source, it is not necessarily "the" source of fibrocytes. CD34 expression has since been found in tissues outside of the BM and on cells that express other hematopoietic markers. Within subcutaneous adipose tissue, $\sim 10 \%$ of uncultured, freshly isolated macrophages obtained from stromal vascular fraction of human lipoaspirates expressed CD34, CD45, and CD206 (91-93). These cells localized in the perivascular region and share characteristics with adipose-derived MSCs and circulating monocytes. In culture, they grew rapidly, after several weeks in 10\% FBS lost expression of CD45, CD14, and CD206, and could also be differentiated into multiple mesenchymal lineages. Therefore, tissue resident macrophages are an abundant source of cells and it is plausible that these cells were the primary source of cells observed within the subcutaneous wound chamber in the original study that identified fibrocytes but failed to show fibrocytes were BM-derived when using chimeric mice that they were BM-derived.

CD34 is also expressed on hematopoietic macrophage progenitors that reside in the adventitia of blood vessels (31, 94). Within healthy WT mice, $8.4 \%$ of cells isolated from the aorta express CD34 compared to only $0.7 \%$ in the blood and $1.5 \%$ in the BM; although, not all adventitial CD34+ cells are of hematopoietic lineage as expression of CD34 is also found on adventitial mesenchymal progenitor cells that do not express hematopoietic markers $(31,95,96)$. Following irradiation, the clonogenic capacity of these adventitial macrophage progenitors was reduced, but these cells were not replenished by circulating cells from the BM or spleen and they were not depleted by clodronate containing liposomes (94). Therefore, this potential source of fibrocytes would persist in chimeric mice following BM transplantation and since the vasculature is abundant in nearly all tissues these adventitial hematopoietic cells could be a local source of fibrocytes throughout the body that are not recently derived from the circulation.

The presence of fibrocytes within a tissue does not require an underlying pathology as fibrocytes have been identified in the heart, spleen, skin, and kidneys of healthy mice $(9,10,14,23,97)$. scRNA-Seq performed on cardiac fibrocytes from healthy mice revealed these cells possess a hybrid phenotype between fibroblasts and macrophages, expressing intermediate levels of canonical macrophage genes (Fcgr1, Cd14, and Ptprc) and fibroblast genes (Col1a1, Pdgfra, and Tcf21) (97). In a separate study, flow cytometry was used to characterize tissue resident macrophages (CD45lo), monocyte-derived macrophages (CD45hi), and fibrocytes (Col1+ CD45+) (23). The number of monocyte-derived fibrocytes was greater in hearts from aged mice (20-30 month-old) as compared to young mice (3-monthold). In addition, median fluorescence intensity for Coll was twice the value in aged hearts compared to young hearts. There was also a population of Col1+ tissue resident macrophages in the heart and this is significant because cardiac tissue resident macrophages arise from yolk sac and fetal monocyte progenitors (98). Yolk sac macrophages precede the formation of definitive hematopoiesis in the BM. Therefore, were any tissue resident yolk sac-derived macrophages to express collagen these would not fit the popular definition for a fibrocyte as a BM-derived cell, though this distinction may be more formal than practical (88). In addition to the heart, the brain and liver are among the few tissues known to retain yolk sac-derived macrophages (98).

The presence of fibrocytes in tissues of healthy animals raises the possibility of a tissue resident fibrocyte population and local proliferation as a potential source of new fibrocytes, but this is not supported by strong evidence. While PBMC-derived fibrocytes cultured in vitro display a doubling time of 3 to 4 days, proliferation in vivo has not been adequately investigated $(4,9)$. A study of fibrocytes in a UUO model of kidney fibrosis did not communicate an attempt to quantify proliferation of resident fibrocytes, but addressed this possibility in the discussion by stating "so far, no proliferation of mature fibrocytes has been found" (14). In a mouse model of asthma, when circulating Col1+CD34+ cells were labeled with the fluorescent red dye PKH-26 and reinjected, after 24 hours the intensity of PKH-26 was slightly reduced indicating that a minority of the cells may have divided (9).

Col1 + CD45+ fibrocytes can also be found in the spleen of healthy individuals, the number of which exceeds the number fibrocytes isolated from blood by approximately an order of magnitude and the obstructed kidney in a UUO fibrosis model by approximately two orders of magnitude $(9,14,19)$. Given the relative number of Col1+ fibrocytes that can be detected within and isolated from the spleen, similar to its known function as a reservoir for monocytes it is worth considering the spleen as a potential reservoir for fibrocytes (99). It remains to be determined whether splenic fibrocytes are readily deployable in response to inflammation or if the spleen functions as a central repository for aged fibrocytes and/or site at which they might undergo recycling similar to erythrocytes in the liver. Alternatively, the spleen may provide a site for fibrocyte 
differentiation, analogous to maturation of $\mathrm{T}$ cells in the thymus. While intriguing, this currently does not have strong support in the literature. Fibrocyte differentiation from monocytes in the spleen was investigated in a UUO kidney fibrosis model. Following obstruction of the kidney, there was an increase in the number of Col1+CD45+ fibrocytes in the spleen (14). Depletion of monocytes using an antibody against CCR2 did not also result in depletion of fibrocytes in the blood or spleen indicating that fibrocytes may not directly differentiate from CCR2+ monocytes. The authors of the UUO kidney model concluded that differentiation of monocytes into fibrocytes within the spleen was unlikely in part because depletion of circulating monocytes did not result in a reduced number of fibrocytes in the spleen.

However, if monocytes do differentiate into fibrocytes, the lack of detectable fibrocyte depletion in the spleen following CCR2+ monocyte depletion has plausible explanations. First, the population of splenic fibrocytes is relatively large. If the rate of fibrocyte differentiation was low and splenic fibrocytes were to possess a relatively long lifespan compared to monocytes, a decrease in splenic fibrocytes due to monocyte depletion or inhibited monocyte infiltration into the spleen might simply be difficult to detect. A second possible explanation requires a bit of background. In mice, two subpopulations of monocytes have been identified, namely classical monocytes $\left(\right.$ Ly6 $\mathrm{C}^{\text {hi }}$ CCR $\left.2+\right)$ and non-classical monocytes (Ly6C ${ }^{\text {lo }}$ CCR2-) (100). In humans, similar subpopulations exist that include classical (CD14+ CD16-), intermediate (CD14+CD16+), and non-classical $\left(\mathrm{CD} 14^{\text {lo }} \mathrm{CD} 16+\right)$ monocytes. Restoration of circulating monocytes following monocytopenia demonstrated sequential transition of monocytes from classical through intermediate to non-classical phenotypes with lifespans of $\sim 1, \sim 4$, and $\sim 7$ days, respectively (101). Classical monocytes are relatively proliferative and resistant to apoptosis compared to non-classical monocytes which appear relatively senescent and are proposed to be terminal differentiated (102). Associated with the differences in surface marker expression are differences in function. Classical monocytes are regarded as pro-inflammatory and migration out of the BM and into sites of inflammation is CCR2-dependent (103). Non-classical monocytes are termed patrolling as they crawl along the lumen of the vasculature. After extravasating into tissue, classical monocytes may give rise to non-classical monocytes, macrophages (both CD206+ and CD206-) and dendritic cells, whereas non-classical monocytes preferentially give rise to CD206+ macrophages (103-105). Returning now to the second potential explanation, if fibrocytes differentiate preferentially from non-classical monocytes within the spleen, one might expect a delay for the depletion of classical monocytes to result in a depletion of non-classical monocytes and subsequent reduction in fibrocyte differentiation such that the effect was not detectable within the 7 days during which this experiment was performed. In other words, the treatment may not have had a direct or immediate effect on the pool of cells actively differentiating into fibrocytes and adequate numbers of these monocyte-fibrocyte intermediates were maintained such that fibrocyte generation was not adversely impacted. Therefore, the lack of detectable change in splenic fibrocyte number following antibody depletion of CCR2+ monocytes in the UUO model suggests that if fibrocytes differentiate from monocytes within the spleen, fibrocytes do not appear to differentiate directly from classical CCR2+ monocytes. Correspondingly, Col1+ cells expressing classical monocyte markers were not observed in the spleen. Splenic fibrocytes may instead differentiate from non-classical CCR2- monocytes, splenic macrophages, or infiltrate as differentiated fibrocytes.

The possibility that fibrocytes might differentiate within the spleen warrants further study. One strategy could be to splenectomize mice and determining if there a subsequent reduction in the number of circulating fibrocytes and/or fibrocytes within tissues following injury. This would rest on the assumption that no compensatory mechanism exists such as alternative sites of fibrocyte differentiation.

Col1+ hematopoietic-derived cells in the circulation, BM, and spleen have largely been interpreted to be newly-derived fibrocytes. Another possibility is that these cells may instead be derived from tissue fibrocytes or Col1+ macrophages that have reentered the circulation allowing them to traffic to the BM and spleen. Regarding Col1+ macrophages, tissue resident macrophages are established during development and these may be supplemented by monocyte-derived macrophages that differentiate after entering a particular tissue. Therefore, one might not expect to observe macrophages within the blood. Yet, in healthy humans $2.6 \%$ of PBMCs expressed the macrophage marker PM-2K (106) and in healthy mice between 0.5 and $1 \%$ of PBMCs expressed F4/80, a similar value to the frequency of fibrocytes reported in the blood (107). In an attempt to explain this phenomenon, macrophage-like cells have been observed in the thoracic duct, which is a terminal lymphatic vessel that drains into the systemic circulation, and macrophages bearing specific tumor or tissue antigens have been detected within the circulation (108-110). In mice, 24 hours following injection of the lipophilic membrane dye dioctadecyloxacarbocyanine (DiO) into the myocardium $\sim 2 \%$ of macrophages in the spleen and $\sim 5 \%$ of macrophages in the $\mathrm{BM}$ were $\mathrm{DiO}+$, values that increased if mice were subjected to coronary artery ligation immediately following injection of $\mathrm{DiO}$ (111). These observations appear to confirm that Col1+ macrophages may return to the circulation either directly or indirectly through the lymphatic system where they may then traffic to the BM and spleen (112). Perhaps fibrocytes within tissues may recirculate and traffic by similar mechanisms. Therefore, as an alternative to increased generation or recruitment from the BM, fibrocyte and Col1+ macrophage reentry into the circulation could explain the increased number of fibrocytes observed in the spleen following injury to the kidney, liver, and skin $(10,14,113,114)$.

In the original study that identified fibrocytes, the authors suggested BM-MSCs might be a potential fibrocyte precursors. This now appears highly unlikely since BM-MSCs do not circulate and should not contribute to fibrosis outside of the $\mathrm{BM}$, with the exception of severe bone fracture and BM embolism $(29,66)$. In addition, CD45 is an exclusion criterion for MSCs. Although MSCs have been reported to express 
macrophage markers, acquired expression of CD45 has not been reported on these cells.

Currently, it appears that the origin(s) of fibrocytes and sites of fibrocyte differentiation remain undetermined. Fibrocytes may be minted as a unique lineage within the BM, differentiate from monocytes or tissue resident macrophages, or arise from tissue resident fibrocyte precursors established early during development (Figure 2). Fibrocyte differentiation from precursors may occur within the BM, spleen, or after infiltrating into a particular tissue. Though, if monocytes do differentiate into fibrocytes, classical monocytes appear to require differentiation through an intermediate phenotype such as a non-classical monocyte or macrophage prior to the expression of collagen. Furthermore, fibrocytes may be derived from combinations of these potential sources and the relative contributions of these sources may be tissue and model specific.

\section{DISCUSSION}

After more than 25 years of investigation, the direct contribution of fibrocytes to fibrosis has been reported in tissues throughout the body, yet arguably we still know little about these cells. In particular, there is a lot of uncertainty surrounding the life cycle of these cells. Though by definition these cell must have a hematopoietic origin, the identity of fibrocyte precursors has yet to be determined. In addition, the fate of these cells is unknown after the stimulus for fibrocyte recruitment and differentiation within a tissue resolve. Do fibrocytes undergo

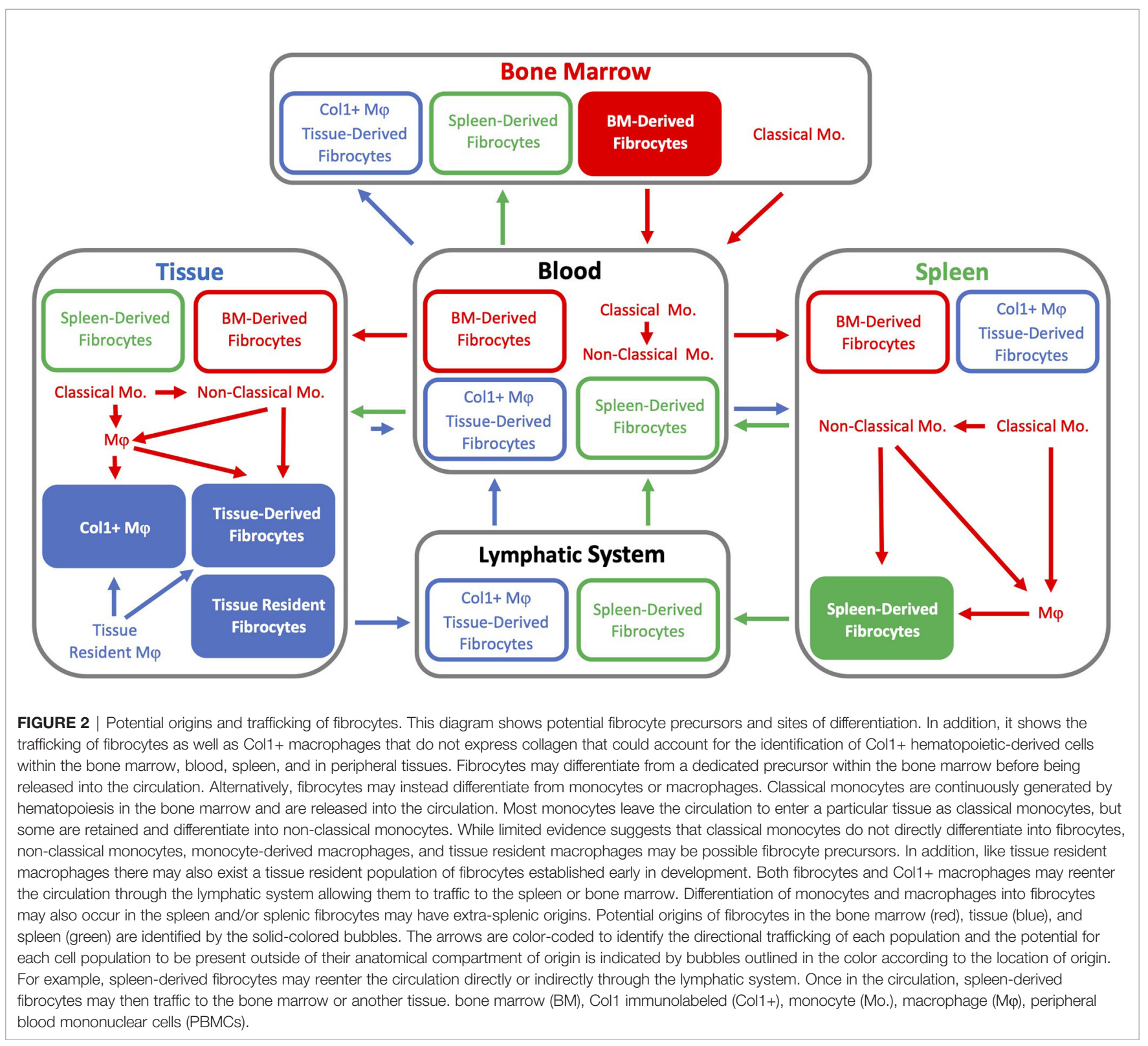


apoptosis, dedifferentiate, or migrate out of the tissue and reenter the circulation to traffic to another site such as the BM or spleen? If fibrocytes do dedifferentiate, for example into a macrophagelike cell, would that diminish the status of fibrocytes as a unique cell type and suggest collagen production is within phenotypic potential of hematopoietic-derived cells that is brought out by certain pathologies, aging, or artificial environments? Most of the fibrosis models provided are of short duration from 1-6 weeks after injury to the time of analysis. In resolving wounds, such as the skin, the presence of fibrocytes decreased after peaking at one week (7). Few studies have investigated the long-term effect of fibrocytes as might be expected as part of a foreign body response surrounding an implant (115). It would be interesting to determine the lifespan of fibrocytes within a particular setting, whether there is continued accumulation throughout chronic inflammation, and whether extended exposure to an inflammatory environment might result in heightened ECM production or increased contractile potential compared to what has been observed acutely.

The combination of stimuli necessary to elicit collagen expression from fibrocyte precursors remains to be determined. Similar to myofibroblast differentiation, TGF- $\beta 1$ may be one such stimulus. TGF- $\beta 1$ supplementation increased the expression of Coll and $\alpha \mathrm{SMA}$ in cultured BM-derived $\mathrm{CD} 11 \mathrm{~b}+$ cells (10). Since this measurement was determined by qPCR performed on pooled cells, it can't be known whether TGF- $\beta 1$ increased the fraction of cells expressing these markers, or increased the expression of these markers only in cells already expressing Col1 and $\alpha$ SMA. TGF- $\beta 1$ also increased the expression of $\alpha$ SMA 4 -fold in cultured human PBMCs as well as their ability to contract collagen gel $(20,22)$. Similarly, another study reported that in cultures of Col1 + CD34+ cells isolated from the peripheral blood, after 6 days in serum free medium $20 \%$ expressed $\alpha$ SMA, but more than $80 \%$ expressed $\alpha$ SMA in the presence of TGF- $\beta 1$ (9).

It may also be worth revisiting the criteria for identifying fibrocytes. When fibrocytes were first described, these cells were shown to express Coll and Col3. Subsequent studies have largely relied on expression of Col1 for fibrocyte identification, but transcriptional analyses have shown that fibrocytes may also produce Col4, Col5, Col6, Col8, Col12 fibrillin, periostin, and biglycan $(5,17)$. A consensus should be established as to whether there exist other ECM proteins for which expression in the absence of Coll expression would be sufficient for a hematopoietic-derived cell to be considered a fibrocyte.

Recent transcriptional analyses based on scRNA-Seq data have demonstrated the potential to vastly expand the ability to identify and characterize fibrocytes in vivo with increased confidence. Though scRNA-Seq is powerful on its own, its future application will likely complement many of the methods described herein including transgenic mice and histology; hence, the motivation for revisiting the strengths and limitations of these strategies for studying fibrocytes. The investigative power of methods like scRNA-Seq may also justify revisiting past experiments limited by the methods applied at the time. In conclusion, the future application of single-cell transcriptional analyses promises to invigorate the study of fibrocytes and accelerate our understanding of this cell type.

\section{AUTHOR CONTRIBUTIONS}

JR and CB conceived and designed the manuscript. JR conducted the literature review and drafted the manuscript. JR and CB critically revised the manuscript. All authors contributed to the article and approved the submitted version.

\section{FUNDING}

This research was supported by U.S. National Institutes of Health grants: R01HL098228, R01HL128602, and R01HL128847, in addition to the Department of Defense Application ID PR170976 Award Number W81XWH-18-1-0518. JR was supported by the American Heart Association under Award Number 18POST33990231.

\section{REFERENCES}

1. Madsen DH, Ingvarsen S, Jurgensen HJ, Melander MC, Kjoller L, Moyer A, et al. The Non-Phagocytic Route of Collagen Uptake: A Distinct Degradation Pathway. J Biol Chem (2011) 286(30):26996-7010. doi: 10. 1074/jbc.M110.208033

2. Bianchetti L, Barczyk M, Cardoso J, Schmidt M, Bellini A, Mattoli S. Extracellular Matrix Remodelling Properties of Human Fibrocytes. J Cell Mol Med (2012) 16(3):483-95. doi: 10.1111/j.1582-4934.2011.01344.x

3. Madsen DH, Leonard D, Masedunskas A, Moyer A, Jurgensen HJ, Peters DE, et al. M2-Like Macrophages Are Responsible for Collagen Degradation Through a Mannose Receptor-Mediated Pathway. J Cell Biol (2013) 202 (6):951-66. doi: 10.1083/jcb.201301081

4. Bucala R, Spiegel LA, Chesney J, Hogan M, Cerami A. Circulating Fibrocytes Define a New Leukocyte Subpopulation That Mediates Tissue Repair. Mol Med (1994) 1(1):71-81. doi: 10.1007/BF03403533

5. Guerrero-Juarez CF, Dedhia PH, Jin S, Ruiz-Vega R, Ma D, Liu Y, et al. Single-Cell Analysis Reveals Fibroblast Heterogeneity and Myeloid-Derived

Adipocyte Progenitors in Murine Skin Wounds. Nat Commun (2019) 10 (1):650. doi: 10.1038/s41467-018-08247-x

6. Kleaveland KR, Velikoff M, Yang J, Agarwal M, Rippe RA, Moore BB, et al. Fibrocytes Are Not an Essential Source of Type I Collagen During Lung Fibrosis. J Immunol (2014) 193(10):5229-39. doi: 10.4049/jimmunol. 1400753

7. Sun M, Wang P, Okubo T, Orringer JS, Voorhees JJ, Fisher GJ, et al. Possible Contribution of Fibrocytes to Increased Type I Collagen Synthesis During the Early Stage of Dermal Wound Repair in Human Skin. J Invest Dermatol (2018) 138(1):240-2. doi: 10.1016/j.jid.2017.08.020

8. Reinhardt JW, Rosado JDR, Barker JC, Lee YU, Best CA, Yi T, et al. Early Natural History of Neotissue Formation in Tissue-Engineered Vascular Grafts in a Murine Model. Regener Med (2019) 14(5):389-408. doi: 10.2217/ rme-2018-0133

9. Schmidt M, Sun G, Stacey MA, Mori L, Mattoli S. Identification of Circulating Fibrocytes as Precursors of Bronchial Myofibroblasts in Asthma. J Immunol (2003) 171(1):380-9. doi: 10.4049/jimmunol.171.1.380

10. Suga H, Rennert RC, Rodrigues M, Sorkin M, Glotzbach JP, Januszyk M, et al. Tracking the Elusive Fibrocyte: Identification and Characterization of 
Collagen-Producing Hematopoietic Lineage Cells During Murine Wound Healing. Stem Cells (2014) 32(5):1347-60. doi: 10.1002/stem.1648

11. Hashimoto N, Jin H, Liu T, Chensue SW, Phan SH. Bone Marrow-Derived Progenitor Cells in Pulmonary Fibrosis. J Clin Invest (2004) 113(2):243-52. doi: $10.1172 /$ jci200418847

12. van Amerongen MJ, Bou-Gharios G, Popa E, van Ark J, Petersen AH, van Dam GM, et al. Bone Marrow-Derived Myofibroblasts Contribute Functionally to Scar Formation After Myocardial Infarction. J Pathol (2008) 214(3):377-86. doi: 10.1002/path.2281

13. Sinha M, Sen CK, Singh K, Das A, Ghatak S, Rhea B, et al. Direct Conversion of Injury-Site Myeloid Cells to Fibroblast-Like Cells of Granulation Tissue. Nat Commun (2018) 9(1):936. doi: 10.1038/s41467-018-03208-w

14. Reich B, Schmidbauer K, Rodriguez Gomez M, Johannes Hermann F, Gobel N, Bruhl H, et al. Fibrocytes Develop Outside the Kidney But Contribute to Renal Fibrosis in a Mouse Model. Kidney Int (2013) 84(1):78-89. doi: $10.1038 / \mathrm{ki} .2013 .84$

15. Haider N, Bosca L, Zandbergen HR, Kovacic JC, Narula N, Gonzalez-Ramos S, et al. Transition of Macrophages to Fibroblast-Like Cells in Healing Myocardial Infarction. J Am Coll Cardiol (2019) 74(25):3124-35. doi: 10.1016/j.jacc.2019.10.036

16. Wang YY, Jiang H, Pan J, Huang XR, Wang YC, Huang HF, et al. Macrophage-To-Myofibroblast Transition Contributes to Interstitial Fibrosis in Chronic Renal Allograft Injury. J Am Soc Nephrol (2017) 28 (7):2053-67. doi: 10.1681/ASN.2016050573

17. Simoes FC, Cahill TJ, Kenyon A, Gavriouchkina D, Vieira JM, Sun X, et al. Macrophages Directly Contribute Collagen to Scar Formation During Zebrafish Heart Regeneration and Mouse Heart Repair. Nat Commun (2020) 11(1):600. doi: 10.1038/s41467-019-14263-2

18. Wang JF, Jiao H, Stewart TL, Shankowsky HA, Scott PG, Tredget EE. Fibrocytes From Burn Patients Regulate the Activities of Fibroblasts. Wound Repair Regener (2007) 15(1):113-21. doi: 10.1111/j.1524-475X.2006.00192.x

19. Crawford JR, Pilling D, Gomer RH. Improved Serum-Free Culture Conditions for Spleen-Derived Murine Fibrocytes. J Immunol Methods (2010) 363(1):9-20. doi: 10.1016/j.jim.2010.09.025

20. Abe R, Donnelly SC, Peng T, Bucala R, Metz CN. Peripheral Blood Fibrocytes: Differentiation Pathway and Migration to Wound Sites. J Immunol (2001) 166(12):7556-62. doi: 10.4049/jimmunol.166.12.7556

21. Mehrad B, Burdick MD, Zisman DA, Keane MP, Belperio JA, Strieter RM. Circulating Peripheral Blood Fibrocytes in Human Fibrotic Interstitial Lung Disease. Biochem Biophys Res Commun (2007) 353(1):104-8. doi: 10.1016/ j.bbrc.2006.11.149

22. Phillips RJ, Burdick MD, Hong K, Lutz MA, Murray LA, Xue YY, et al. Circulating Fibrocytes Traffic to the Lungs in Response to CXCL12 and Mediate Fibrosis. J Clin Invest (2004) 114(3):438-46. doi: 10.1172/ jci200420997

23. Trial J, Heredia CP, Taffet GE, Entman ML, Cieslik KA. Dissecting the Role of Myeloid and Mesenchymal Fibroblasts in Age-Dependent Cardiac Fibrosis. Basic Res Cardiol (2017) 112(4):34. doi: 10.1007/s00395-017-0623-4

24. Ozono Y, Shide K, Kameda T, Kamiunten A, Tahira Y, Sekine M, et al. Neoplastic Fibrocytes Play an Essential Role in Bone Marrow Fibrosis in Jak2V617F-Induced Primary Myelofibrosis Mice. Leukemia (2021) 35 (2):454-67. doi: 10.1038/s41375-020-0880-3

25. Ohishi M, Ono W, Ono N, Khatri R, Marzia M, Baker EK, et al. A Novel Population of Cells Expressing Both Hematopoietic and Mesenchymal Markers Is Present in the Normal Adult Bone Marrow and Is Augmented in a Murine Model of Marrow Fibrosis. Am J Pathol (2012) 180(2):811-8. doi: 10.1016/j.ajpath.2011.10.028

26. Salib M, Girerd S, Girerd N, Marz W, Scharnagl H, Massy ZA, et al. Serum Markers of Fibrosis, Cardiovascular and All-Cause Mortality in Hemodialysis Patients: The AURORA Trial. Clin Res Cardiol (2021). doi: 10.1007/s00392-021-01898-9

27. Organ LA, Duggan AR, Oballa E, Taggart SC, Simpson JK, Kang'ombe AR, et al. Biomarkers of Collagen Synthesis Predict Progression in the PROFILE Idiopathic Pulmonary Fibrosis Cohort. Respir Res (2019) 20(1):148. doi: 10.1186/s12931-019-1118-7

28. Sidney LE, Branch MJ, Dunphy SE, Dua HS, Hopkinson A. Concise Review: Evidence for CD34 as a Common Marker for Diverse Progenitors. Stem Cells (2014) 32(6):1380-9. doi: 10.1002/stem.1661
29. Kramann R, Schneider RK, DiRocco DP, Machado F, Fleig S, Bondzie PA, et al. Perivascular Gli1+ Progenitors Are Key Contributors to InjuryInduced Organ Fibrosis. Cell Stem Cell (2015) 16(1):51-66. doi: 10.1016/ j.stem.2014.11.004

30. Quan TE, Cowper S, Wu SP, Bockenstedt LK, Bucala R. Circulating Fibrocytes: Collagen-Secreting Cells of the Peripheral Blood. Int J Biochem Cell Biol (2004) 36(4):598-606. doi: 10.1016/j.biocel.2003.10.005

31. Psaltis PJ, Harbuzariu A, Delacroix S, Witt TA, Holroyd EW, Spoon DB, et al. Identification of a Monocyte-Predisposed Hierarchy of Hematopoietic Progenitor Cells in the Adventitia of Postnatal Murine Aorta. Circulation (2012) 125(4):592-603. doi: 10.1161/CIRCULATIONAHA.111.059360

32. Varcoe RL, Mikhail M, Guiffre AK, Pennings G, Vicaretti M, Hawthorne WJ, et al. The Role of the Fibrocyte in Intimal Hyperplasia. J Thromb Haemostasis (2006) 4:1125-33. doi: 10.1111/j.1538-7836.2006.01924.x

33. Hollinshead M, Sanderson J, Vaux DJ. Vector Alkaline Phosphatase Substrate Blue III: One Substrate for Brightfield Histochemistry and High Resolution Fluorescence Imaging by Confocal Laser Scanning Microscopy. Histochemical J (1998) 30(8):577-81. doi: 10.1023/a:1003227032513

34. Das A, Sinha M, Datta S, Abas M, Chaffee S, Sen CK, et al. Monocyte and Macrophage Plasticity in Tissue Repair and Regeneration. Am J Pathol (2015) 185(10):2596-606. doi: 10.1016/j.ajpath.2015.06.001

35. Bron S, Henry L, Faes-Van't Hull E, Turrini R, Vanhecke D, Guex N, et al. TIE-2-Expressing Monocytes Are Lymphangiogenic and Associate Specifically With Lymphatics of Human Breast Cancer. Oncoimmunology (2016) 5(2):e1073882. doi: 10.1080/2162402X.2015.1073882

36. Chakraborty R, Saddouk FZ, Carrao AC, Krause DS, Greif DM, Martin KA. Promoters to Study Vascular Smooth Muscle. Arterioscler Thromb Vasc Biol (2019) 39(4):603-12. doi: 10.1161/ATVBAHA.119.312449

37. Bersell K, Choudhury S, Mollova M, Polizzotti BD, Ganapathy B, Walsh S, et al. Moderate and High Amounts of Tamoxifen in AlphaMHCMerCreMer Mice Induce a DNA Damage Response, Leading to Heart Failure and Death. Dis Model Mech (2013) 6(6):1459-69. doi: 10.1242/ dmm.010447

38. Lexow J, Poggioli T, Sarathchandra P, Santini MP, Rosenthal N. Cardiac Fibrosis in Mice Expressing an Inducible Myocardial-Specific Cre Driver. Dis Model Mech (2013) 6(6):1470-6. doi: 10.1242/dmm.010470

39. Koitabashi N, Bedja D, Zaiman AL, Pinto YM, Zhang M, Gabrielson KL, et al. Avoidance of Transient Cardiomyopathy in Cardiomyocyte-Targeted Tamoxifen-Induced MerCreMer Gene Deletion Models. Circ Res (2009) 105 (1):12-5. doi: 10.1161/CIRCRESAHA.109.198416

40. Higashi AY, Ikawa T, Muramatsu M, Economides AN, Niwa A, Okuda T, et al. Direct Hematological Toxicity and Illegitimate Chromosomal Recombination Caused by the Systemic Activation of CreERT2. J Immunol (2009) 182(9):5633-40. doi: 10.4049/jimmunol.0802413

41. Blum KM, Roby LC, Zbinden JC, Chang YC, Mirhaidari GJM, Reinhardt JW, et al. Sex and Tamoxifen Confound Murine Experimental Studies in Cardiovascular Tissue Engineering. Sci Rep (2021) 11(1):8037. doi: 10.1038/ s41598-021-87006-3

42. Roostalu U, Aldeiri B, Albertini A, Humphreys N, Simonsen-Jackson M, Wong JKF, et al. Distinct Cellular Mechanisms Underlie Smooth Muscle Turnover in Vascular Development and Repair. Circ Res (2018) 122(2):26781. doi: 10.1161/CIRCRESAHA.117.312111

43. Jiang X, Kalajzic Z, Maye P, Braut A, Bellizzi J, Mina M, et al. Histological Analysis of GFP Expression in Murine Bone. J Histochem Cytochem (2005) 53(5):593-602. doi: 10.1369/jhc.4A6401.2005

44. Barisic-Dujmovic T, Boban I, Clark SH. Fibroblasts/myofibroblasts That Participate in Cutaneous Wound Healing Are Not Derived From Circulating Progenitor Cells. J Cell Physiol (2010) 222(3):703-12. doi: 10.1002/jcp.21997

45. Higashiyama R, Moro T, Nakao S, Mikami K, Fukumitsu H, Ueda Y, et al. Negligible Contribution of Bone Marrow-Derived Cells to Collagen Production During Hepatic Fibrogenesis in Mice. Gastroenterology (2009) 137(4):1459-66 el. doi: 10.1053/j.gastro.2009.07.006

46. Higashiyama R, Nakao S, Shibusawa Y, Ishikawa O, Moro T, Mikami K, et al. Differential Contribution of Dermal Resident and Bone Marrow-Derived Cells to Collagen Production During Wound Healing and Fibrogenesis in Mice. J Invest Dermatol (2011) 131(2):529-36. doi: 10.1038/jid.2010.314

47. Bou-Gharios G, Garrett LA, Rossert J, Niederreither K, Eberspaecher H, Smith C, et al. A Potent Far-Upstream Enhancer in the Mouse Proa2(I) 
Collagen Gene Regulates Expression of Reporter Genes in Transgenic Mice. J Cell Biol (1996) 134:1333-44. doi: 10.1083/jcb.134.5.1333

48. Mollmann H, Nef HM, Kostin S, von Kalle C, Pilz I, Weber M, et al. Bone Marrow-Derived Cells Contribute to Infarct Remodelling. Cardiovasc Res (2006) 71(4):661-71. doi: 10.1016/j.cardiores.2006.06.013

49. Okabe M, Ikawa M, Kominami K, Nakanishi T, Nishimune Y. "Green Mice" as a Source of Ubiquitous Green Cells. FEBS Lett (1997) 407:313-9. doi: 10.1016/S0014-5793(97)00313-X

50. Yata Y, Scanga A, Gillan A, Yang L, Reif S, Breindl M, et al. DNase IHypersensitive Sites Enhance Alpha1(I) Collagen Gene Expression in Hepatic Stellate Cells. Hepatology (2003) 37(2):267-76. doi: 10.1053/ jhep.2003.50067

51. Moore-Morris T, Cattaneo P, Guimaraes-Camboa N, Bogomolovas J, Cedenilla M, Banerjee I, et al. Infarct Fibroblasts Do Not Derive From Bone Marrow Lineages. Circ Res (2018) 2018(122):583-90. doi: 10.1161/ CIRCRESAHA.117.311490

52. LeBleu VS, Taduri G, O'Connell J, Teng Y, Cooke VG, Woda C, et al. Origin and Function of Myofibroblasts in Kidney Fibrosis. Nat Med (2013) 19 (8):1047-53. doi: 10.1038/nm.3218

53. Lin SL, Kisseleva T, Brenner DA, Duffield JS. Pericytes and Perivascular Fibroblasts Are the Primary Source of Collagen-Producing Cells in Obstructive Fibrosis of the Kidney. Am J Pathol (2008) 173(6):1617-27. doi: 10.2353/ajpath.2008.080433

54. Kisseleva T, Uchinami H, Feirt N, Quintana-Bustamante O, Segovia JC, Schwabe RF, et al. Bone Marrow-Derived Fibrocytes Participate in Pathogenesis of Liver Fibrosis. J Hepatol (2006) 45(3):429-38. doi: 10.1016/j.jhep.2006.04.014

55. Manfra DJ, Chen S-C, Yang T-Y, Sullivan L, Wiekowski MT, Abbondanzo S, et al. Leukocytes Expressing Green Fluorescent Protein as Novel Reagents for Adoptive Cell Transfer and Bone Marrow Transplantation Studies. Am J Pathol (2001) 158:41-7. doi: 10.1016/S0002-9440(10)63942-9

56. Yokota T, Kawakami Y, Nagai Y, Ma JX, Tsai JY, Kincade PW, et al. Bone Marrow Lacks a Transplantable Progenitor for Smooth Muscle Type AlphaActin-Expressing Cells. Stem Cells (2006) 24(1):13-22. doi: 10.1634/ stemcells.2004-0346

57. Tanaka K, Sata M, Hirata Y, Nagai R. Diverse Contribution of Bone Marrow Cells to Neointimal Hyperplasia After Mechanical Vascular Injuries. Circ Res (2003) 93(8):783-90. doi: 10.1161/01.RES.0000096651. 13001.B4

58. Lu Y, Kamel-El Sayed SA, Wang K, Tiede-Lewis LM, Grillo MA, Veno PA, et al. Live Imaging of Type I Collagen Assembly Dynamics in Osteoblasts Stably Expressing GFP and Mcherry-Tagged Collagen Constructs. J Bone Miner Res (2018) 33(6):1166-82. doi: 10.1002/jbmr.3409

59. Kramann R, Machado F, Wu H, Kusaba T, Hoeft K, Schneider RK, et al. Parabiosis and Single-Cell RNA Sequencing Reveal a Limited Contribution of Monocytes to Myofibroblasts in Kidney Fibrosis. JCI Insight (2018) 3 (9):1-14. doi: 10.1172/jci.insight.99561

60. Yang J, Wheeler SE, Velikoff M, Kleaveland KR, LaFemina MJ, Frank JA, et al. Activated Alveolar Epithelial Cells Initiate Fibrosis Through Secretion of Mesenchymal Proteins. Am J Pathol (2013) 183(5):1559-70. doi: 10.1016/ j.ajpath.2013.07.016

61. Cui J, Wahl RL, Shen T, Fisher SJ, Recker E, Ginsburg D, et al. Bone Marrow Cell Trafficking Following Intravenous Administration. $\mathrm{Br} J$ Haematol (1999) 1999(107):895-902. doi: 10.1046/j.1365-2141.1999.01779.x

62. Campbell NG, Kaneko M, Shintani Y, Narita T, Sawhney V, Coppen SR, et al. Cell Size Critically Determines Initial Retention of Bone Marrow Mononuclear Cells in the Heart After Intracoronary Injection: Evidence From a Rat Model. PloS One (2016) 11(7):e0158232. doi: 10.1371/ journal.pone. 0158232

63. Li SH, Lai TY, Sun Z, Han M, Moriyama E, Wilson B, et al. Tracking Cardiac Engraftment and Distribution of Implanted Bone Marrow Cells: Comparing Intra-Aortic, Intravenous, and Intramyocardial Delivery. J Thorac Cardiovasc Surg (2009) 137(5):1225-33 e1. doi: 10.1016/j.jtcvs.2008.11.001

64. Schrepfer S, Deuse T, Reichenspurner H, Fischbein MP, Robbins RC, Pelletier MP. Stem Cell Transplantation: The Lung Barrier. Transplant Proc (2007) 39(2):573-6. doi: 10.1016/j.transproceed.2006.12.019

65. Cilloni D, Carlo-Stella C, Falzetti F, Sammarelli G, Regazzi E, Colla S, et al. Limited Engraftment Capacity of Bone Marrow-Derived Mesenchymal
Cells Following T-Cell-Depleted Hematopoietic Stem Cell Transplantation. Blood (2000) 96(10):3637-43. doi: 10.1182/blood.V96.10.3637

66. Hoogduijn MJ, Verstegen MMA, Ungela AU, Korevaar SS, Roemeling-van Rhijn MR, Merino A, et al. No Evidence for Circulating Mesenchymal Stem Cells in Patients With Organ Injury. Stem Cells Dev (2014) 23(19):2328-35. doi: $10.1089 / \mathrm{scd} .2014 .0269$

67. Wu Y, Zhao RC, Tredget EE. Concise Review: Bone Marrow-Derived Stem/ Progenitor Cells in Cutaneous Repair and Regeneration. Stem Cells (2010) 28 (5):905-15. doi: 10.1002/stem.420

68. He Q, Wan C, Li G. Concise Review: Multipotent Mesenchymal Stromal Cells in Blood. Stem Cells (2007) 25(1):69-77. doi: 10.1634/stemcells.20060335

69. Bustelo XR, Rubin SD, Suen K-L, Carrasco D, Barbacid M. Developmental Expression of vav Protooncogene. Cell Growth Differ (1993) 4:297-308.

70. Zambidis ET, Peault B, Park TS, Bunz F, Civin CI. Hematopoietic Differentiation of Human Embryonic Stem Cells Progresses Through Sequential Hematoendothelial, Primitive, and Definitive Stages Resembling Human Yolk Sac Development. Blood (2005) 106(3):860-70. doi: 10.1182/blood-2004-11-4522

71. Shankman LS, Gomez D, Cherepanova OA, Salmon M, Alencar GF, Haskins RM, et al. KLF4-Dependent Phenotypic Modulation of Smooth Muscle Cells has a Key Role in Atherosclerotic Plaque Pathogenesis. Nat Med (2015) 21 (6):628-37. doi: 10.1038/nm.3866

72. Chappell J, Harman JL, Narasimhan VM, Yu H, Foote K, Simons BD, et al. Extensive Proliferation of a Subset of Differentiated, Yet Plastic, Medial Vascular Smooth Muscle Cells Contributes to Neointimal Formation in Mouse Injury and Atherosclerosis Models. Circ Res (2016) 119(12):1313-23. doi: 10.1161/CIRCRESAHA.116.309799

73. Rosenzweig M, Connole M, Glickman R, Yue S-PS, Noren B, DeMaria M, et al. Induction of Cytotoxic T Lymphocyte and Antibody Responses to Enhanced Green Fluorescent Protein Following Transplantation of Transduced CD34+ Hematopoietic Cells. Gene Ther (2001) 97(7):1951-9. doi: 10.1182/blood.v97.7.1951

74. Pilling D, Fan T, Huang D, Kaul B, Gomer RH. Identification of Markers That Distinguish Monocyte-Derived Fibrocytes From Monocytes, Macrophages, and Fibroblasts. PloS One (2009) 4(10):e7475. doi: 10.1371/ journal.pone. 0007475

75. Klingberg F, Chau G, Walraven M, Boo S, Koehler A, Chow ML, et al. The Fibronectin ED-A Domain Enhances Recruitment of Latent TGF-BetaBinding Protein-1 to the Fibroblast Matrix. J Cell Sci (2018) 131(5):1-12. doi: $10.1242 /$ jcs. 201293

76. Bianco P, Cao X, Frenette PS, Mao JJ, Robey PG, Simmons PJ, et al. The Meaning, the Sense and the Significance: Translating the Science of Mesenchymal Stem Cells Into Medicine. Nat Med (2013) 19(1):35-42. doi: $10.1038 / \mathrm{nm} .3028$

77. Lech M, Anders HJ. Macrophages and Fibrosis: How Resident and Infiltrating Mononuclear Phagocytes Orchestrate All Phases of Tissue Injury and Repair. Biochim Biophys Acta (2013) 1832(7):989-97. doi: 10.1016/j.bbadis.2012.12.001

78. Wynn TA, Vannella KM. Macrophages in Tissue Repair, Regeneration, and Fibrosis. Immunity (2016) 44(3):450-62. doi: 10.1016/j.immuni.2016.02.015

79. Murray LA, Chen Q, Kramer MS, Hesson DP, Argentieri RL, Peng X, et al. TGF-Beta Driven Lung Fibrosis Is Macrophage Dependent and Blocked by Serum Amyloid P. Int J Biochem Cell Biol (2011) 43(1):154-62. doi: 10.1016/ j.biocel.2010.10.013

80. Tomasek JJ, Gabbiani G, Hinz B, Chaponnier C, Brown RA. Myofibroblasts and Mechano-Regulation of Connective Tissue Remodelling. Nat Rev Mol Cell Biol (2002) 3(5):349-63. doi: 10.1038/nrm809

81. Hinz B, Celetta G, Tomasek JJ, Gabbiani G, Chaponnier C. Alpha-Smooth Muscle Actin Expression Upregulates Fibroblast Contractile Activity. Mol Biol Cell (2001) 12(September 2001):2730-41. doi: 10.1091/mbc.12.9.2730

82. Mouton AJ, DeLeon-Pennell KY, Rivera Gonzalez OJ, Flynn ER, Freeman TC, Saucerman JJ, et al. Mapping Macrophage Polarization Over the Myocardial Infarction Time Continuum. Basic Res Cardiol (2018) 113 (4):26. doi: 10.1007/s00395-018-0686-x

83. Corish P, Tyler-Smith C. Attenuation of Green Fluorescent Protein Half-Life in Mammalian Cells. Protein Eng (1999) 12(12):1035-40. doi: 10.1093/ protein/12.12.1035 
84. Kumar S, Sunagar R, Pham G, Gosselin EJ, Nalin D. Ex Vivo Antigen-Pulsed PBMCs Generate Potent and Long Lasting Immunity to Infection When Administered as a Vaccine. Vaccine (2017) 35(7):1080-6. doi: 10.1016/ j.vaccine.2016.12.035

85. Corkum CP, Ings DP, Burgess C, Karwowska S, Kroll W, Michalak TI. Immune Cell Subsets and Their Gene Expression Profiles From Human PBMC Isolated by Vacutainer Cell Preparation Tube (CPT) and Standard Density Gradient. BMC Immunol (2015) 16:48. doi: 10.1186/s12865-015-0113-0

86. Bucala R. Fibrocytes at 20 Years. Mol Med (2015) 21 Suppl:1, S3-5. doi: 10.2119/molmed.2015.00043

87. Chesney J, Metz CN, Stavitsky AB, Bacher M, Bucala R. Regulated Production of Type I Collagen and Inflammatory Cytokines by Peripheral Blood Fibrocytes. J Immunol (1998) 160:419-25.

88. Wu Y, Hirschi KK. Tissue-Resident Macrophage Development and Function. Front Cell Dev Biol (2020) 8:617879. doi: 10.3389/fcell.2020. 617879

89. Vaage J, Lindblad WJ. Production of Collagen Type I by Mouse Peritoneal Macrophages. J Leukocyte Biol (1990) 48(3):274-80. doi: 10.1002/jlb.48.3.274

90. Bain CC, Hawley CA, Garner H, Scott CL, Schridde A, Steers NJ, et al. LongLived Self-Renewing Bone Marrow-Derived Macrophages Displace EmbryoDerived Cells to Inhabit Adult Serous Cavities. Nat Commun (2016) 7: ncomms11852. doi: $10.1038 /$ ncomms 11852

91. Traktuev DO, Merfeld-Clauss S, Li J, Kolonin M, Arap W, Pasqualini R, et al. A Population of Multipotent CD34-Positive Adipose Stromal Cells Share Pericyte and Mesenchymal Surface Markers, Reside in a Periendothelial Location, and Stabilize Endothelial Networks. Circ Res (2008) 102(1):77-85. doi: 10.1161/CIRCRESAHA.107.159475

92. Eto H, Ishimine H, Kinoshita K, Watanabe-Susaki K, Kato H, Doi K, et al. Characterization of Human Adipose Tissue-Resident Hematopoietic Cell Populations Reveals a Novel Macrophage Subpopulation With CD34 Expression and Mesenchymal Multipotency. Stem Cells Dev (2013) 22 (6):985-97. doi: 10.1089/scd.2012.0442

93. Morris ME, Beare JE, Reed RM, Dale JR, LeBlanc AJ, Kaufman CL, et al. Systemically Delivered Adipose Stromal Vascular Fraction Cells Disseminate to Peripheral Artery Walls and Reduce Vasomotor Tone Through a CD11b+ Cell-Dependent Mechanism. Stem Cells Transl Med (2015) 4(4):369-80. doi: 10.5966/sctm.2014-0252

94. Psaltis PJ, Puranik AS, Spoon DB, Chue CD, Hoffman SJ, Witt TA, et al. Characterization of a Resident Population of Adventitial Macrophage Progenitor Cells in Postnatal Vasculature. Circ Res (2014) 115(3):364-75. doi: 10.1161/CIRCRESAHA.115.303299

95. Hu Y, Zhang Z, Torsney E, Afzal AR, Davison F, Metzler B, et al. Abundant Progenitor Cells in the Adventitia Contribute to Atherosclerosis of Vein Grafts in ApoE-Deficient Mice. J Clin Invest (2004) 113(9):1258-65. doi: $10.1172 /$ jci19628

96. Passman JN, Dong XR, Wu SP, Maguire CT, Hogan KA, Bautch VL, et al. A Sonic Hedgehog Signaling Domain in the Arterial Adventitia Supports Resident Sca1+ Smooth Muscle Progenitor Cells. Proc Natl Acad Sci USA (2008) 105(27):9349-54. doi: 10.1073/pnas.0711382105

97. Skelly DA, Squiers GT, McLellan MA, Bolisetty MT, Robson P, Rosenthal NA, et al. Single-Cell Transcriptional Profiling Reveals Cellular Diversity and Intercommunication in the Mouse Heart. Cell Rep (2018) 22(3):600-10. doi: 10.1016/j.celrep.2017.12.072

98. Epelman S, Lavine KJ, Beaudin AE, Sojka DK, Carrero JA, Calderon B, et al. Embryonic and Adult-Derived Resident Cardiac Macrophages Are Maintained Through Distinct Mechanisms at Steady State and During Inflammation. Immunity (2014) 40(1):91-104. doi: 10.1016/j.immuni.2013.11.019

99. Swirski FK, Nahrendorf M, Etzrodt M, Wildgruber M, Cortez-Retamozo V, Panizzi P, et al. Identification of Splenic Reservoir Monocytes and Their Deployment to Inflammatory Sites. Science (2009) 325(5940):612-6. doi: $10.1126 /$ science. 1175202

100. Sunderkotter C, Nikolic T, Dillon MJ, Van Rooijen N, Stehling M, Drevets DA, et al. Subpopulations of Mouse Blood Monocytes Differ in Maturation Stage and Inflammatory Response. J Immunol (2004) 172(7):4410-7. doi: 10.4049/jimmunol.172.7.4410

101. Patel AA, Zhang Y, Fullerton JN, Boelen L, Rongvaux A, Maini AA, et al. The Fate and Lifespan of Human Monocyte Subsets in Steady State and Systemic Inflammation. J Exp Med (2017) 214(7):1913-23. doi: 10.1084/jem.20170355
102. Ong SM, Hadadi E, Dang TM, Yeap WH, Tan CT, Ng TP, et al. The ProInflammatory Phenotype of the Human Non-Classical Monocyte Subset Is Attributed to Senescence. Cell Death Dis (2018) 9(3):266. doi: 10.1038/ s41419-018-0327-1

103. Kratofil RM, Kubes P, Deniset JF. Monocyte Conversion During Inflammation and Injury. Arterioscler Thromb Vasc Biol (2017) 37(1):3542. doi: 10.1161/ATVBAHA.116.308198

104. Olingy CE, San Emeterio CL, Ogle ME, Krieger JR, Bruce AC, Pfau DD, et al. Non-Classical Monocytes Are Biased Progenitors of Wound Healing Macrophages During Soft Tissue Injury. Sci Rep (2017) 7(1):447. doi: 10.1038/s41598-017-00477-1

105. Dal-Secco D, Wang J, Zeng Z, Kolaczkowska E, Wong CH, Petri B, et al. A Dynamic Spectrum of Monocytes Arising From the In Situ Reprogramming of CCR2+ Monocytes at a Site of Sterile Injury. J Exp Med (2015) 212(4):44756. doi: $10.1084 /$ jem. 20141539

106. Hung CH, Wang CC, Suen JL, Sheu CC, Kuo CH, Liao WT, et al. Altered Pattern of Monocyte Differentiation and Monocyte-Derived TGF-Betal in Severe Asthma. Sci Rep (2018) 8(1):919. doi: 10.1038/s41598-017-19105-z

107. Wu X, Xu W, Feng X, He Y, Liu X, Gao Y, et al. TNF-A Mediated Inflammatory Macrophage Polarization Contributes to the Pathogenesis of Steroid-Induced Osteonecrosis in Mice. Int J Immunopathol Pharmacol (2015) 28(3):351-61. doi: 10.1177/0394632015593228

108. van den Bossche WBL, Vincent A, Teodosio C, Koets J, Taha A, Kleijn A, et al. Monocytes Carrying GFAP Detect Glioma, Brain Metastasis and Ischaemic Stroke, and Predict Glioblastoma Survival. Brain Commun (2021) 3(1):fcaa215. doi: 10.1093/braincomms/fcaa215

109. Bell EB, Botham J. Antigen Transport. I. DemonstrationAnd Characterization of Cells Laden With Antigen in Thoracic Duct Lymph and Blood. Immunology (1982) 47:477-87.

110. Faber TJ, Japink D, Leers MP, Sosef MN, von Meyenfeldt MF, Nap M. Activated Macrophages Containing Tumor Marker in Colon Carcinoma: Immunohistochemical Proof of a Concept. Tumour Biol (2012) 33(2):43541. doi: 10.1007/s13277-011-0269-z

111. Heidt T, Courties G, Dutta P, Sager HB, Sebas M, Iwamoto Y, et al. Differential Contribution of Monocytes to Heart Macrophages in SteadyState and After Myocardial Infarction. Circ Res (2014) 115(2):284-95. doi: 10.1161/CIRCRESAHA.115.303567

112. Varol C, Yona S, Jung S. Origins and Tissue-Context-Dependent Fates of Blood Monocytes. Immunol Cell Biol (2009) 87(1):30-8. doi: 10.1038/icb.2008.90

113. Scholten D, Reichart D, Paik YH, Lindert J, Bhattacharya J, Glass CK, et al. Migration of Fibrocytes in Fibrogenic Liver Injury. Am J Pathol (2011) 179 (1):189-98. doi: 10.1016/j.ajpath.2011.03.049

114. Kisseleva T, von Kockritz-Blickwede M, Reichart D, McGillvray SM, Wingender G, Kronenberg M, et al. Fibrocyte-Like Cells Recruited to the Spleen Support Innate and Adaptive Immune Responses to Acute Injury or Infection. J Mol Med (Berl) (2011) 89(10):997-1013. doi: 10.1007/s00109-0110756-0

115. Baker DW, Tsai YT, Weng H, Tang L. Alternative Strategies to Manipulate Fibrocyte Involvement in the Fibrotic Tissue Response: Pharmacokinetic Inhibition and the Feasibility of Directed-Adipogenic Differentiation. Acta Biomater (2014) 10(7):3108-16. doi: 10.1016/j.actbio.2014.03.011

Conflict of Interest: The authors declare that the research was conducted in the absence of any commercial or financial relationships that could be construed as a potential conflict of interest.

Publisher's Note: All claims expressed in this article are solely those of the authors and do not necessarily represent those of their affiliated organizations, or those of the publisher, the editors and the reviewers. Any product that may be evaluated in this article, or claim that may be made by its manufacturer, is not guaranteed or endorsed by the publisher.

Copyright (c) 2021 Reinhardt and Breuer. This is an open-access article distributed under the terms of the Creative Commons Attribution License (CC BY). The use, distribution or reproduction in other forums is permitted, provided the original author(s) and the copyright owner(s) are credited and that the original publication in this journal is cited, in accordance with accepted academic practice. No use, distribution or reproduction is permitted which does not comply with these terms. 